
\title{
R Research Soure \\ Robust Visual Digital Data Authentication using Hybrid Transform with Human Visual System Characteristics
}

Satyanarayana Murty.P ( $\sim$ psn.murty71@gmail.com )

Vignan's Institute of Information Technology https://orcid.org/0000-0001-7933-0739

Purna Ramesh Addanki

Vishnu Institute of Technology

\section{Research}

Keywords: Robust, Image watermarking, Reference Image, Blocks, discrete wavelet transform, singular value decomposition

Posted Date: December 28th, 2020

DOI: https://doi.org/10.21203/rs.3.rs-127191/v1

License: (c) (i) This work is licensed under a Creative Commons Attribution 4.0 International License.

Read Full License 


\title{
Robust Visual Digital Data Authentication using Hybrid Transform with Human Visual System Characteristics
}

\author{
Dr. Satyanarayana Murthy.P \\ Professor \\ Department of ECE \\ Vignan Institute of Information and Technology \\ Duvvada \\ Visakhspatnam (dt) \\ Andhra Pradesh \\ India \\ Psn,murty71@gmail.com
}

\author{
Dr. Addanki Purna Ramesh \\ Professor \\ Department of ECE \\ Vishnu Institute of Technology \\ Bhimavaram, \\ West Godavari (Dt) \\ Andhra Pradesh \\ India \\ purnarameshaddanki@gmail.com
}

\begin{abstract}
Robust watermarking proposals supported on human visual characteristics with a series of hybrid transform of type discrete wavelet transform (DWT) followed by singular value decomposition (SVD) is wished-for. By analyzing the matrices $\mathrm{U}$ or V through SVD, it is bringing into being that there stay alive a well-built relationship amid the internal column elements of $U$ or internal row elements of V. Hence, this work will make the most of these chattels for image watermarking. At the outset, visual digital data is segregated into $8 \times 8$ non-overlapping pixel blocks and each block is processed for brinks by using the algorithm of detection for a canny brink. An appropriate block is decided to pick in such a way that the number of brinks in each block is only about or equal to a threshold. A threshold is defined by finding the mean of the brinks in each block of the host visual digital data. Using these appropriate blocks, we will form an image of reference. This reference image is processed by a series of operations DWT-SVD. Then, the watermark is implanted by adapting the nth column of the $U$ matrix of the host image with the nth column of the $\mathrm{U}$ matrix of the watermark image. The same operation is applied on the $\mathrm{V}$ matrix instead of a column vector, use a row vector. The adapted relation is wont to retrieve a watermark. The experimental findings demonstrate that the ideal watermarking algorithm will guarantee that the typical image processing operations and geometric attacks are invisible and more stable. The efficiency of this proposed method is out of shape than other proposed methods examined in this research.
\end{abstract}

Keywords: Robust, Image watermarking, Reference Image, Blocks, discrete wavelet transform and singular value decomposition

\section{Introduction}

Since the emergence of the internet and computerized innovation around the world, the creation and usage of computerized data has expanded rapidly these days. Individuals can process, trade, and store advanced substances more easily than at any other time in recent memory. In either event, a further scheme of protection problems has arisen against this bit of leeway, for instance, 
unhindered repetition, regulation, and distribution of sight and sound. Thus, assurances of possession and substance checks have become critical issues. Watermarking is known to be a credible solution to solving these problems in the middle of the latest strategies. Using the advanced watermarking technique, a mystery picture is introduced into a creative picture to point out that the scattered object renders a subsequent watermarked image the same one. At last, the extraction technique is used to recover watermark images. Digital watermarking has numerous uses such as copyright security, broadcast surveillance, web archiving, image authentication, and fingerprinting, annotation, and privacy control [1].

There are two embedding areas accessible under the digital watermarking scheme, which is a spatial region and a transformation/frequency area [2]. The mapping of the spatial region and the retrieval of the visual watermark is achieved when adjusting the intensity values of the various chosen pixels [3-6]. Transform domain algorithms are Discrete Cosine Transform [7-12] and Discrete Wavelet Transform [13-17]. Watermarking techniques in this domain have high computational unpredictability. Experimental characteristics of SVD technology are made to be widely used in watermarking algorithms [18-20]. Massive numbers of watermarking plans are incorporated into the singular values of the cover image. However, despite its comprehensive computing, SVD alone is not preferred and hybrid SVD-based watermarking plans are constructed. As a consequence, a few watermarking procedures focused on SVD insert watermarks addicted to single vectors ( $\mathrm{U}$ or $\mathrm{V}$ ) or both vectors instead of the singular values. This wipes out the likelihood of a false positive issue that may happen.

Block-based imaging watermarking approaches have possible advantages, one of which is the ability to treat each component independently. In specific, the watermark is placed on blocks, which are objects or locations of the image's fundamental precept details such as surface and edges.

Lai et al have implemented an advanced SVD scheme based on blocks [18]. They alienated the multitude image into $8 \times 8$ unidentified blocks and picked the right HVS-dependent blocks. In the initial column of the U matrix, the watermark bits were mounted by looking at the entries for each column. Exploratory outcomes and hypothetical examinations exhibited the proficiency of the plan suggested by Lai under diverse kinds of image controls. Their technique showed improved execution contrasted with past schemes in the writing and was a more effective technique.

Authors [19] wished-for a watermarking approach focused happening the discreet fractional transformation of Fourier (DFrFT) and Visual Cryptography. A technique is surprisingly successful against a specific attack on image processing. Under their system, the host image is separated into non-covered squares, and specific squares are chosen to use the pseudo-arbitrary number generator.

Chang et al [20] applied an SVD strategy focused on columns. The host picture is split down into non-overlapping sections, and the SVD is used for each segment as well. Hence, calculating all coefficients of the non-zero S-segment evaluates the multifaceted complexity of every node. The most attractive non-zero coefficients are suggested to judge the most important critical blocks. In 
this method, these dynamic blocks are chosen through inclusion to maintain visual continuity. Ultimately, the insertion is carried out by measuring the relation among the coefficients in the initial column of the $U$. This approach was effective for the various general images of attack handling.

Chung et al [21] reviewed their instructions and checked their imperceptibility and capability adequacy. The test results showed that the instructions included all the SVD-based watermarking system's strength and peak signal to noise (PSNR) focal points. The main proposition was that the modification of the coefficients in the $U$ column caused fewer noticeable manipulations than the row vectors.

Fan et al [22] performed several inquiries that were focused on Chung et al's advice [21]. A computational review was conducted and the test findings were analyzed to establish a reliable watermarking scheme focused on the SVD. These tests checked the viability of the assumptions suggested improving the SVD's imperceptibility and robustness.

Makbol et al [23] is featured a block-based project that uses entropy and edge entropy as HVS properties to acquire correct watermark integration objects. Blocks with low entropy significances are selected as the preeminent regions for adding watermarks. The security issues are getting better by encrypting a piece of important information using AES-195 bit.

Chang and Ali [24] initiated a blend of DWT, SVD, Fractional Fourier Transform, and visual encryption is included in the lossless image watermarking technique. The technique uses DWT and FFT to pile up the first cover image in the unaltered area. FFT selects the random area at that point to embed the image of a watermark.

Ali Fatahegi et al. [25] suggested another power full digital image watermarking technique. To begin with, the cover image degrades into non-overlapping blocks. At that point, they use the careful edge position and support vector machine (SVM) classification strategy to manage these blocks into smooth and smooth classes. The VC strategy is used to generate dual image shares: the master share created with block sorting outcomes and the owner share created using the master share with the binary log of the watermark.

An epic block-based scalable solution to watermarking is introduced in this paper. The reference image is shaped on the standing of the measure of edges in each block of the image. The blocks are arranged with the goal that the amount of edges in each block is not exactly or identical to cut off the collection. The cut-off collection is chosen so that by thinking about the mean of an assortment of edges in each block of the image. A progression of DWT-SVD changes is applied to the reference image. The column $\mathrm{U}$ and the row $\mathrm{V}$ of the reference image are individually adjusted with the column $\mathrm{U}$ and row $\mathrm{V}$ of the secret image. The proposed work shows great imperceptibility and rousts to various image handling attacks 


\section{Related work}

This section is given to the short clarifications of the ideas being utilized in the proposed plan, for example, transforming the original image to DWT, and SVD.

\subsection{Discrete Wavelet Transform (DWT)}

DWT is a popular reversible transition in the frequency field, and it functions through tiny waves called the wavelet of increasing frequency. DWT decays or splits two-dimensional images into four sub frequency classes, such as LL resolution band, HL horizontal band, LH vertical band, and $\mathrm{HH}$ diagonal sub band. In the DWT decay, enormous wavelet coefficients reflect the most important vitality or picture details. The lower-sub band LL has the maximum coefficients and corresponds to much of the picture details. DWT is conducted by continuous low-pass and highpass analytics as seen in Fig. 1, to adapt the G[n] picture signal to the size, horizontal, vertical and diagonal sub-bands. Equation 1 indicates the detection of large loops, and Eq. 2 Displays a lowpass filter on the picture signal $G[n]$.

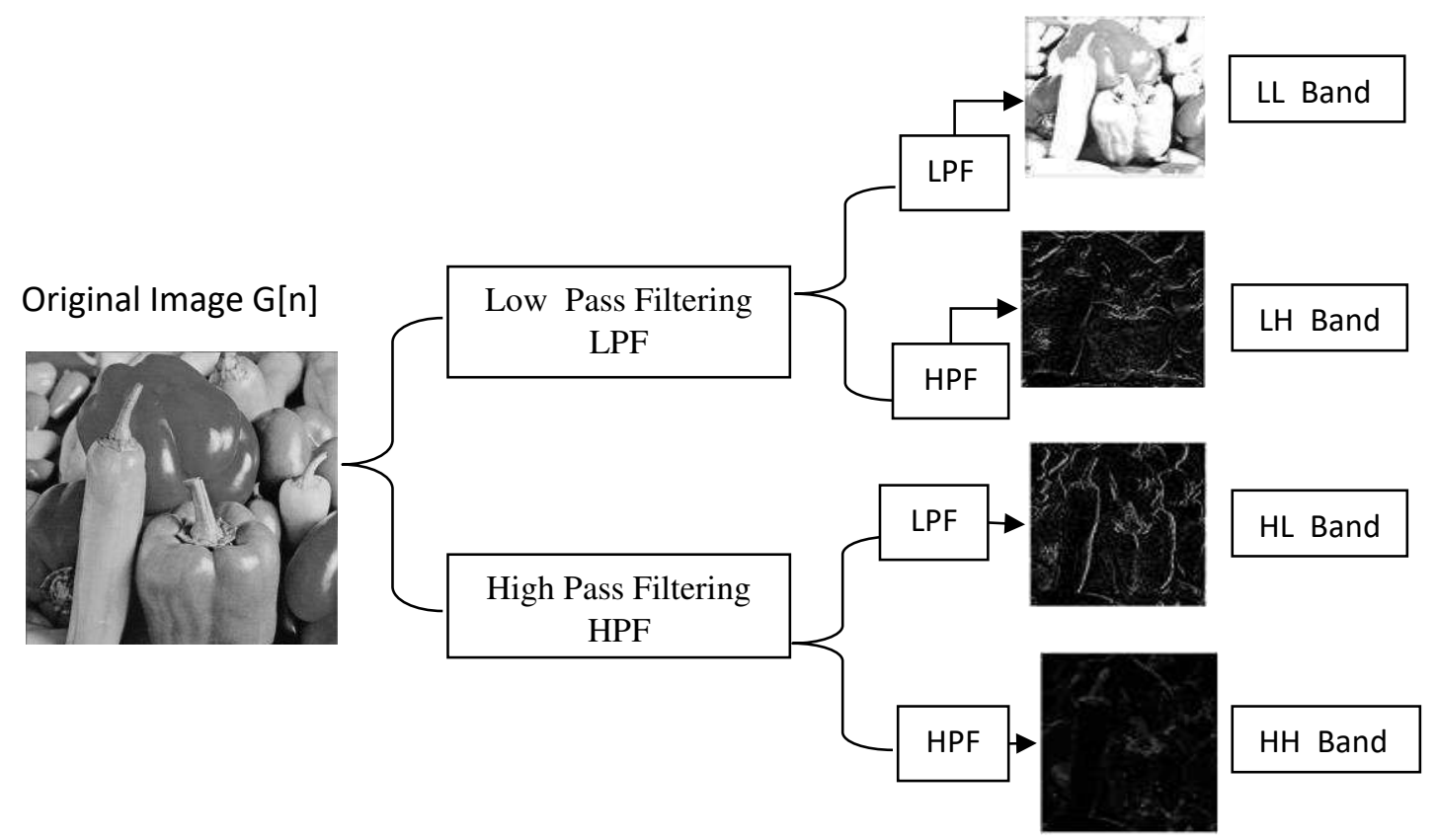

Figure 1: Decomposition of cover image By DWT

$$
\begin{aligned}
& y \operatorname{yigh}[\mathrm{p}]=\sum_{\mathrm{n}} \mathrm{G}[\mathrm{n}] \cdot \mathrm{l}[2 \mathrm{p}-1] \\
& y \operatorname{low}[\mathrm{p}]=\sum_{\mathrm{n}} \mathrm{G}[\mathrm{n}] \cdot \mathrm{m}[2 \mathrm{p}-1]
\end{aligned}
$$

Equation 1

Equation 2

\subsection{Singular Value Decomposition (SVD)}


The SVD gives a mathematically steady lattice disintegration that can be utilized for an assortment of purposes and is ensured to exist. Let us assume that $\mathrm{P}$ is an $\mathrm{N} \times \mathrm{N}$ square matrix with rank $\mathrm{r}, \mathrm{r}$ $\leq \mathrm{N}$. The $\mathrm{SVD}$ of $\mathrm{P}$ is represented as

$$
\begin{gathered}
P=U S V^{T}=\left[U_{1}, U_{2}, \ldots \ldots \ldots \ldots U_{N}\right]\left[\begin{array}{cccc}
S_{1} & 0 & \cdots & 0 \\
0 & S_{2} & \cdots & 0 \\
\vdots & 0 & \cdots & \vdots \\
0 & 0 & \cdots & S_{N}
\end{array}\right]\left[V_{1}, V_{2}, \ldots \ldots \ldots \ldots V_{N}\right]^{T} \\
=\left[\begin{array}{ccc}
U_{1,1} & \cdots & U_{1, N} \\
U_{2,1} & \cdots & U_{2, N} \\
\vdots & \ddots & \vdots \\
U_{N, 1} & \cdots & U_{N, N}
\end{array}\right]\left[\begin{array}{cccc}
S_{1} & 0 & \cdots & 0 \\
0 & S_{2} & \cdots & 0 \\
\vdots & 0 & \cdots & \vdots \\
0 & 0 & \cdots & S_{N}
\end{array}\right]\left[\begin{array}{ccc}
V_{1,1} & \cdots & V_{1, N} \\
V_{2,1} & \cdots & V_{2, N} \\
\vdots & \ddots & \vdots \\
V_{N, 1} & \cdots & V_{N, N}
\end{array}\right]^{T}
\end{gathered}
$$

Equation-3 is shown that the specified matrix is decomposed into three matrices by using SVD. Where $\mathrm{U}$ and $\mathrm{V}$ are $\mathrm{N} \times \mathrm{N}$ orthogonal matrices and $\mathrm{S}$ is $\mathrm{N} \times \mathrm{N}$ singular, Diagonal matrix with diagonal entries $\mathrm{S}_{\mathrm{i}}$ 's (singular values) satisfying $\mathrm{S}_{1} \geq \mathrm{S}_{2} \geq \mathrm{S}_{3} \geq \ldots \mathrm{S}_{\mathrm{r}}>\mathrm{S}_{\mathrm{r}+1}=\ldots \mathrm{S}_{\mathrm{N}}=0$.

To understand our proposed problem easy, take that the input sub-image ' $\mathrm{P}$ ' is a $4 \times 4$ array and the SVD of ' $\mathrm{P}$ ' is fixed by

$$
P=\left[\begin{array}{llll}
G_{1} & G_{2} & G_{3} & G_{4} \\
G_{5} & G_{6} & G_{7} & G_{8} \\
G_{9} & G_{10} & G_{11} & G_{12} \\
G_{13} & G_{14} & G_{15} & G_{16}
\end{array}\right] \quad \text { and } \quad[D E F]=\operatorname{svd}(P)
$$

On multiplication of three matrices $\mathrm{D}, \mathrm{E}$, and $\mathrm{F}$

$$
\begin{aligned}
& \mathrm{P}=\mathrm{DEF}^{\mathrm{T}}=\left[\begin{array}{llll}
d_{1} & d_{2} & d_{3} & d_{4} \\
d_{5} & d_{6} & d_{7} & d_{8} \\
d_{9} & d_{10} & d_{11} & d_{12} \\
d_{13} & d_{14} & d_{15} & d_{16}
\end{array}\right]\left[\begin{array}{cccc}
e_{1} & 0 & 0 & 0 \\
0 & e_{2} & 0 & 0 \\
0 & 0 & e_{3} & 0 \\
0 & 0 & 0 & e_{4}
\end{array}\right]\left[\begin{array}{cccc}
f_{1} & f_{2} & f_{3} & f_{4} \\
f_{5} & f_{6} & f_{7} & f_{8} \\
f_{9} & f_{10} & f_{11} & f_{12} \\
f_{13} & f_{14} & f_{15} & f_{16}
\end{array}\right]^{\mathrm{T}} \\
& \mathrm{G}_{1}=\mathrm{d}_{1} \mathrm{e}_{1} \mathrm{f}_{1}+\mathrm{d}_{2} \mathrm{e}_{2} \mathrm{f}_{2}+\mathrm{d}_{3} \mathrm{e}_{3} \mathrm{f}_{3}+\mathrm{d}_{4} \mathrm{e}_{4} \mathrm{f}_{4} \quad \mathrm{G}_{9}=\mathrm{d}_{9} \mathrm{e}_{1} \mathrm{f}_{1}+\mathrm{d}_{10} \mathrm{e}_{2} \mathrm{f}_{2}+\mathrm{d}_{11} \mathrm{e}_{3} \mathrm{f}_{3}+\mathrm{d}_{12} \mathrm{e}_{4} \mathrm{f}_{4} \\
& \mathrm{G}_{2}=\mathrm{d}_{1} \mathrm{e}_{1} \mathrm{f}_{5}+\mathrm{d}_{2} \mathrm{e}_{2} \mathrm{f}_{6}+\mathrm{d}_{3} \mathrm{e}_{3} \mathrm{f}_{7}+\mathrm{d}_{4} \mathrm{e}_{4} \mathrm{f}_{8} \quad \mathrm{G}_{10}=\mathrm{d}_{9} \mathrm{e}_{1} \mathrm{f}_{5}+\mathrm{d}_{10} \mathrm{e}_{2} \mathrm{f}_{6}+\mathrm{d}_{11} \mathrm{e}_{3} \mathrm{f}_{7}+\mathrm{d}_{12} \mathrm{e}_{4} \mathrm{f}_{8} \\
& \mathrm{G}_{3}=\mathrm{d}_{1} \mathrm{e}_{1} \mathrm{f}_{9}+\mathrm{d}_{2} \mathrm{e}_{2} \mathrm{f}_{10}+\mathrm{d}_{3} \mathrm{e}_{3} \mathrm{f}_{11}+\mathrm{d}_{4} \mathrm{e}_{4} \mathrm{f}_{12} \quad \mathrm{G}_{11}=\mathrm{d}_{9} \mathrm{e}_{1} \mathrm{f}_{9}+\mathrm{d}_{10} \mathrm{e}_{2} \mathrm{f}_{10}+\mathrm{d}_{11} \mathrm{e}_{3} \mathrm{f}_{11}+\mathrm{d}_{12} \mathrm{e}_{4} \mathrm{f}_{12} \\
& \mathrm{G}_{4}=\mathrm{d}_{1} \mathrm{e}_{1} \mathrm{f}_{13}+\mathrm{d}_{2} \mathrm{e}_{2} \mathrm{f}_{14}+\mathrm{d}_{3} \mathrm{e}_{3} \mathrm{f}_{15}+\mathrm{d}_{4} \mathrm{e}_{4} \mathrm{f}_{16} \quad \mathrm{G}_{12}=\mathrm{d}_{9} \mathrm{e}_{1} \mathrm{f}_{13}+\mathrm{d}_{10} \mathrm{e}_{2} \mathrm{f}_{14}+\mathrm{d}_{11} \mathrm{e}_{3} \mathrm{f}_{15}+\mathrm{d}_{12} \mathrm{e}_{4} \mathrm{f}_{16} \\
& \mathrm{G}_{5}=\mathrm{d}_{5} \mathrm{e}_{1} \mathrm{f}_{1}+\mathrm{d}_{6} \mathrm{e}_{2} \mathrm{f}_{2}+\mathrm{d}_{7} \mathrm{e}_{3} \mathrm{f}_{3}+\mathrm{d}_{8} \mathrm{e}_{4} \mathrm{f}_{4} \quad \mathrm{G}_{13}=\mathrm{d}_{13} \mathrm{e}_{1} \mathrm{f}_{1}+\mathrm{d}_{14} \mathrm{e}_{2} \mathrm{f}_{2}+\mathrm{d}_{15} \mathrm{e}_{3} \mathrm{f}_{3}+\mathrm{d}_{16} \mathrm{e}_{4} \mathrm{f}_{4} \\
& \mathrm{G}_{6}=\mathrm{d}_{5} \mathrm{e}_{1} \mathrm{f}_{5}+\mathrm{d}_{6} \mathrm{e}_{2} \mathrm{f}_{6}+\mathrm{d}_{7} \mathrm{e}_{3} \mathrm{f}_{7}+\mathrm{d}_{8} \mathrm{e}_{4} \mathrm{f}_{8} \quad \mathrm{G}_{14}=\mathrm{d}_{13} \mathrm{e}_{1} \mathrm{f}_{5}+\mathrm{d}_{14} \mathrm{e}_{2} \mathrm{f}_{6}+\mathrm{d}_{15} \mathrm{e}_{3} \mathrm{f}_{7}+\mathrm{d}_{16} \mathrm{e}_{4} \mathrm{f}_{8} \\
& \mathrm{G}_{7}=\mathrm{d}_{5} \mathrm{e}_{1} \mathrm{f}_{9}+\mathrm{d}_{6} \mathrm{e}_{2} \mathrm{f}_{10}+\mathrm{d}_{7} \mathrm{e}_{3} \mathrm{f}_{11}+\mathrm{d}_{8} \mathrm{e}_{4} \mathrm{f}_{12} \quad \mathrm{G}_{15}=\mathrm{d}_{13} \mathrm{e}_{1} \mathrm{f}_{9}+\mathrm{d}_{14} \mathrm{e}_{2} \mathrm{f}_{10}+\mathrm{d}_{15} \mathrm{e}_{3} \mathrm{f}_{11}+\mathrm{d}_{16} \mathrm{e}_{4} \mathrm{f}_{12} \\
& \mathrm{G}_{8}=\mathrm{d}_{5} \mathrm{e}_{1} \mathrm{f}_{13}+\mathrm{d}_{6} \mathrm{e}_{2} \mathrm{f}_{14}+\mathrm{d}_{7} \mathrm{e}_{3} \mathrm{f}_{15}+\mathrm{d}_{8} \mathrm{e}_{4} \mathrm{f}_{1} \quad \mathrm{G}_{16}=\mathrm{d}_{13} \mathrm{e}_{1} \mathrm{f}_{13}+\mathrm{d}_{14} \mathrm{e}_{2} \mathrm{f}_{14}+\mathrm{d}_{15} \mathrm{e}_{3} \mathrm{f}_{15}+\mathrm{d}_{16} \mathrm{e}_{4} \mathrm{f}_{16}
\end{aligned}
$$




\subsection{Extension of Work}

If we observe the pixel values of $P$, all the elements contain singular values $\left\{e_{i} \mid i=1,2,3,4\right\}$.

Consider a model that in the event that we make the components of the initial column of U- matrix $\left\{G_{i} \mid i=1,5,9,13\right\}$ equivalent to zero, at that point every one of the pixels $\left\{G_{i} \mid 5 \leq i \leq 16\right\}$ is given by the total of three terms rather than four terms, showing an even change for every one of the twelve pixels. To comprehend this obviously, after multiplication, consider four pixels $\mathrm{G}_{1}, \mathrm{G}_{5}, \mathrm{G}_{9}$, and $\mathrm{G}_{13}$ which are given by $\mathrm{G}_{1}=\mathrm{d}_{1} \mathrm{e}_{1} \mathrm{f}_{1}+\mathrm{d}_{2} \mathrm{e}_{2} \mathrm{f}_{2}+\mathrm{d}_{3} \mathrm{e}_{3} \mathrm{f}_{3}+\mathrm{d}_{4} \mathrm{e}_{4} \mathrm{f}_{4}, \mathrm{G}_{5}=\mathrm{d}_{5} \mathrm{e}_{1} \mathrm{f}_{1}+\mathrm{d}_{6} \mathrm{e}_{2} \mathrm{f}_{2}+\mathrm{d}_{7} \mathrm{e}_{3} \mathrm{f}_{3}+$ $\mathrm{d}_{8} \mathrm{e}_{4} \mathrm{f}_{4}, \mathrm{G}_{9}=\mathrm{d}_{9} \mathrm{e}_{1} \mathrm{f}_{1}+\mathrm{d}_{10} \mathrm{e}_{2} \mathrm{f}_{2}+\mathrm{d}_{11} \mathrm{e}_{3} \mathrm{f}_{3}+\mathrm{d}_{12} \mathrm{e}_{4} \mathrm{f}_{4}, \mathrm{G}_{13}=\mathrm{d}_{13} \mathrm{e}_{1} \mathrm{f}_{1}+\mathrm{d}_{14} \mathrm{e}_{2} \mathrm{f}_{2}+\mathrm{d}_{15} \mathrm{e}_{3} \mathrm{f}_{3}+\mathrm{d}_{16} \mathrm{e}_{4} \mathrm{f}_{4}$ respectively. In our model, the slanting components are connected as $e_{1} \geq e_{2} \geq e_{3} \geq e_{4}=0$. So the change of first column includes the significant alteration of critical commitment of e1 to all the pixels. We can watch this comparative change among the rest of the pixels of $\mathrm{P}$.

For example, a case of $4 \times 4$ block $\mathrm{P}$ got from a digital image and by performing SVD on $\mathrm{P}$ matrix we get three components $\mathrm{U}, \mathrm{S}$ and $\mathrm{V}$

$$
\begin{gathered}
P=\left[\begin{array}{rrrr}
128 & 115 & 113 & 89 \\
28 & 56 & 90 & 1 \\
25 & 45 & 25 & 55 \\
184 & 32 & 9 & 15
\end{array}\right] \\
=\left[\begin{array}{ccccc}
-0.7577 & -0.3446 & -0.2187 & -0.5093 \\
-0.2894 & -0.4297 & 0.7582 & 0.3958 \\
-0.2270 & -0.2163 & -0.5954 & 0.7397 \\
-0.5391 & 0.8061 & 0.1509 & 0.1918
\end{array}\right]\left[\begin{array}{rrrrr}
289.6876 & 0 & 0 & 0 \\
0 & 128.4304 & 0 & 0 \\
0 & 0 & 58.1265 & 0 \\
0 & 0 & 0 & 3.7453
\end{array}\right] \\
{\left[\begin{array}{llll}
-0.7248 & 0.6756 & 0.1053 & -0.0845 \\
-0.4515 & -0.3709 & -0.0800 & 0.8076 \\
-0.4218 & -0.5900 & 0.5161 & -0.4557 \\
-0.3048 & -0.2406 & -0.8462 & -0.3648
\end{array}\right]}
\end{gathered}
$$

\begin{tabular}{|c|c|c|c|c|c|c|c|c|c|c|c|c|c|c|c|}
\hline \multicolumn{16}{|c|}{$\begin{array}{r}\text { Table 1: Theoretical change of column values by } \\
\text { Sub image data }\end{array}$} \\
\hline \multicolumn{4}{|c|}{128} & \multicolumn{4}{|c|}{115} & \multicolumn{4}{|c|}{113} & \multicolumn{4}{|c|}{89} \\
\hline \multicolumn{4}{|c|}{28} & \multicolumn{4}{|c|}{36} & \multicolumn{4}{|c|}{90} & \multicolumn{4}{|c|}{1} \\
\hline \multicolumn{4}{|c|}{25} & \multicolumn{4}{|c|}{45} & \multicolumn{4}{|c|}{25} & \multicolumn{4}{|c|}{55} \\
\hline \multicolumn{4}{|c|}{184} & \multicolumn{4}{|c|}{32} & \multicolumn{4}{|c|}{9} & \multicolumn{4}{|c|}{15} \\
\hline \multicolumn{4}{|c|}{$\begin{array}{c}\text { Modification in U1 } \\
\text { column }\end{array}$} & \multicolumn{4}{|c|}{$\begin{array}{l}\text { Modification in U2 } \\
\text { column }\end{array}$} & \multicolumn{4}{|c|}{$\begin{array}{l}\text { Modification in U3 } \\
\text { column }\end{array}$} & \multicolumn{4}{|c|}{$\begin{array}{c}\text { Modification in U4 } \\
\text { column }\end{array}$} \\
\hline $\mathbf{0}$ & 16 & 20 & 22 & 158 & 99 & 87 & 78 & 129 & 114 & 120 & 78 & 128 & 117 & 112 & \begin{tabular}{|l|l|}
88 \\
\end{tabular} \\
\hline 0 & 18 & 55 & 0 & 77 & 43 & 64 & 0 & 23 & 60 & 67 & 38 & 28 & 55 & 91 & 2 \\
\hline 0 & 15 & 0 & 35 & 42 & 34 & 8 & 48 & 29 & 42 & 43 & 26 & 25 & 43 & 26 & 56 \\
\hline
\end{tabular}




\begin{tabular}{|l|l|l|l|l|l|l|l|l|l|l|l|l|l|l|l|}
$\mathbf{7 1}$ & 0 & 0 & 0 & 108 & $\mathbf{6 6}$ & 66 & 37 & 183 & 33 & $\mathbf{4}$ & 22 & 184 & 31 & 9 & $\mathbf{1 5}$ \\
\hline
\end{tabular}

From the above conversation and table 1, we can see that altering the U1 column, thus, includes adjusting $\mathrm{e}_{1}$ with the goal that the pixel esteems will encounter an immense change which will cause major noticeable mutilation. On the off chance that we apply a similar examination for residual $U$ columns $\left\{U_{i} \mid 2 \leq i \leq 4\right\}$, as long as ' $i$ ' is expanding, pixel esteems will encounter little change which brings about less noticeable mutilation from table 1 . Because of this reality, an adjustment in the $\mathrm{i}^{\text {th }}$ segment impacts a little change in columns that are directing to the $\mathrm{i}^{\text {th }}$ column and a major change in columns that are after the $i^{\text {th }}$ column.

By applying a similar investigation to the row vector of $\mathrm{V}^{\mathrm{T}}$ part, an adjustment in $\mathrm{k}^{\text {th }}$ line impacts a little change in lines which are managing to $\mathrm{k}^{\text {th }}$ line and a major change in lines which are after the $\mathrm{k}^{\text {th }}$ line. The affiliation between impeccability (PSNR) and normalized cross-correlation (NCC) contrarily adores each other and also the equivalent is accessible within the writing. Presently our perception can take care of the issue of contrarily relative to one another. The table-2 is demonstrated that the delineation of obvious contortion and compares the standardized relationship of various images in columns of U matrix after SVD.

\begin{tabular}{|l|c|c|c|c|c|c|c|c|c|c|}
\hline \multicolumn{8}{|c|}{ Table 2: Standardized relationship of various images in columns of U matrix after SVD } \\
\hline \multirow{2}{*}{ Image } & \multicolumn{2}{|c|}{ U-1 column } & \multicolumn{2}{c|}{ U-8 column } & U-16 column & \multicolumn{2}{|c|}{ U-32 column } & \multicolumn{2}{|c|}{ U-64 column } \\
\cline { 2 - 12 } & PSNR & NCC & PSNR & NCC & PSNR & NCC & PSNR & NCC & PSNR & NCC \\
\hline Lena & 34.12 & 0.8467 & 44.68 & 0.9916 & 47.45 & 0.9850 & 51.70 & 0.9983 & 55.39 & 1.0000 \\
\hline Lake & 34.31 & 0.8231 & 44.75 & 0.9973 & 47.53 & 0.9951 & 50.37 & 0.9970 & 53.70 & 1.0000 \\
\hline Peppers & 34.26 & 0.8466 & 44.82 & 0.9739 & 47.11 & 0.9984 & 52.26 & 0.9964 & 56.70 & 1.0000 \\
\hline sBoat & 33.52 & 0.8318 & 46.77 & 0.9876 & 49.00 & 0.9900 & 51.54 & 0.9983 & 55.30 & 1.0000 \\
\hline Baboon & 34.14 & 0.8411 & 46.05 & 0.9606 & 48.13 & 0.9967 & 49.54 & 0.9980 & 51.21 & 0.9996 \\
\hline Pirate & 35.22 & 0.8582 & 44.66 & 0.9971 & 46.88 & 0.9907 & 50.46 & 0.9994 & 53.32 & 0.9999 \\
\hline Average & 34.26 & 0.8413 & 45.29 & 0.9847 & 47.68 & 0.9927 & 50.98 & 0.9979 & 54.27 & 0.9999 \\
\hline
\end{tabular}

\section{Proposed method}

To install a watermark $\mathrm{W}$ of size $\mathrm{a} \times \mathrm{a}$ into a host image $\mathrm{I}$ of size $\mathrm{N} \times \mathrm{N}$, we play out a progression of sending transforms that is talked about above and with the assistance of block diagram is appeared in Fig. 2. The planned theme consists of three steps one is reference image formation, the other is watermark image embedding, and another one is watermark extracting.

\subsection{Reference image formation}

Stage 1: Consider a cover image I of size $\mathrm{N} \times \mathrm{N}$.

Stage 2: Cover image I is portioned into blocks, size $n \times n$.

Stage 3: Find various edges in each block by utilizing a canny edge discovery technique.

Stage 4: The quantity of edges in each block is orchestrated in plunging request and determined the Mean of the number of edges. This Mean is considered as a threshold. Given this threshold, the vital blocks are viewed as which are significantly higher than or equivalent to a threshold. 
Those blocks are considered huge obstructs that are utilized for making the reference image, size $\mathrm{p} \times \mathrm{p}$.

Stage 5: Formation of the reference image is as showed up in fig 2 (a).

\subsection{Watermark embedding procedure}

Stage 1: The reference image is signified by $I_{\text {ref }}$.

Stage 2: Apply DWT on the reference image $I_{\text {ref }}$, which partitions reference image into four domains by using equation 4 , for example $L L_{\text {ref }}, L H_{\text {ref }}, H L_{r e f}$ and $H H_{\text {ref }}$

$$
\left[L L_{r e f}, L H_{\text {ref }}, H L_{r e f}, H H_{r e f}\right]=\left(I_{\text {ref }}, ' h a a r^{\prime}\right)
$$

Stage 3: Take $L H_{r e f}$ and apply SVD by using equation 5, this activity gives three frameworks $U_{\text {ref }}$ ,$S_{\text {ref }}$ and $V_{\text {ref }}$.

$$
\left[U_{\text {ref }}, S_{\text {ref }}, V_{\text {ref }},\right]=\operatorname{svd}\left(L H_{\text {ref }}\right)
$$

Where $U_{\text {ref }}=\left[U_{\text {ref } 1}, U_{\text {ref } 2}, U_{\text {ref } 3} \ldots \ldots \ldots \ldots . U_{\text {refn }}\right]$

$V_{\text {ref }}=\left[V_{\text {ref } 1}, V_{\text {ref } 2}, V_{\text {ref } 3} \ldots \ldots \ldots \ldots V_{\text {refn }}\right]$

Stage 4: Consider a watermark $\mathrm{W}$ of size $\mathrm{a} \times \mathrm{a}$ and apply SVD as shown in equation 5 , this activity gives three frameworks $U_{w}, S_{w}$ and $V_{w}$.

Where $U_{w}=\left[U_{1 w}, U_{2 w}, U_{3 w} \ldots \ldots \ldots \ldots U_{n w}\right]$

$$
V_{w}=\left[V_{1 w}, V_{2 w}, V_{3 w} \ldots \ldots \ldots V_{n w}\right]
$$

Stage 5: To implant, the watermark into the cover image, alter any column of $U_{\text {nref }}(\mathrm{n}=1,2,3$ n) with any column of $U_{n w}$ (the same column as $U_{r e f n}$ ) from the following equation 6.

$$
U_{\text {embedn }}=U_{n r e f}+\beta * U_{n w}
$$

Stage 6: To insert the watermark into the spread picture, alter any row of $V_{\text {nref }}(\mathrm{n}=1,2,3$ $\ldots \ldots . . . n$ ) with any row of $V_{n w}$ (same row as $U_{r e f n}$ ) from the following equation 7.

$V_{\text {embedn }}=V_{\text {nref }}+\beta * V_{n w}$

Stage 7: Now perform inverse SVD utilizing the accompanying equation 8

$$
W_{\text {svd }}=U_{\text {embedn }} * S_{\text {ref }} * V_{V_{\text {embedn }}}^{Y}
$$




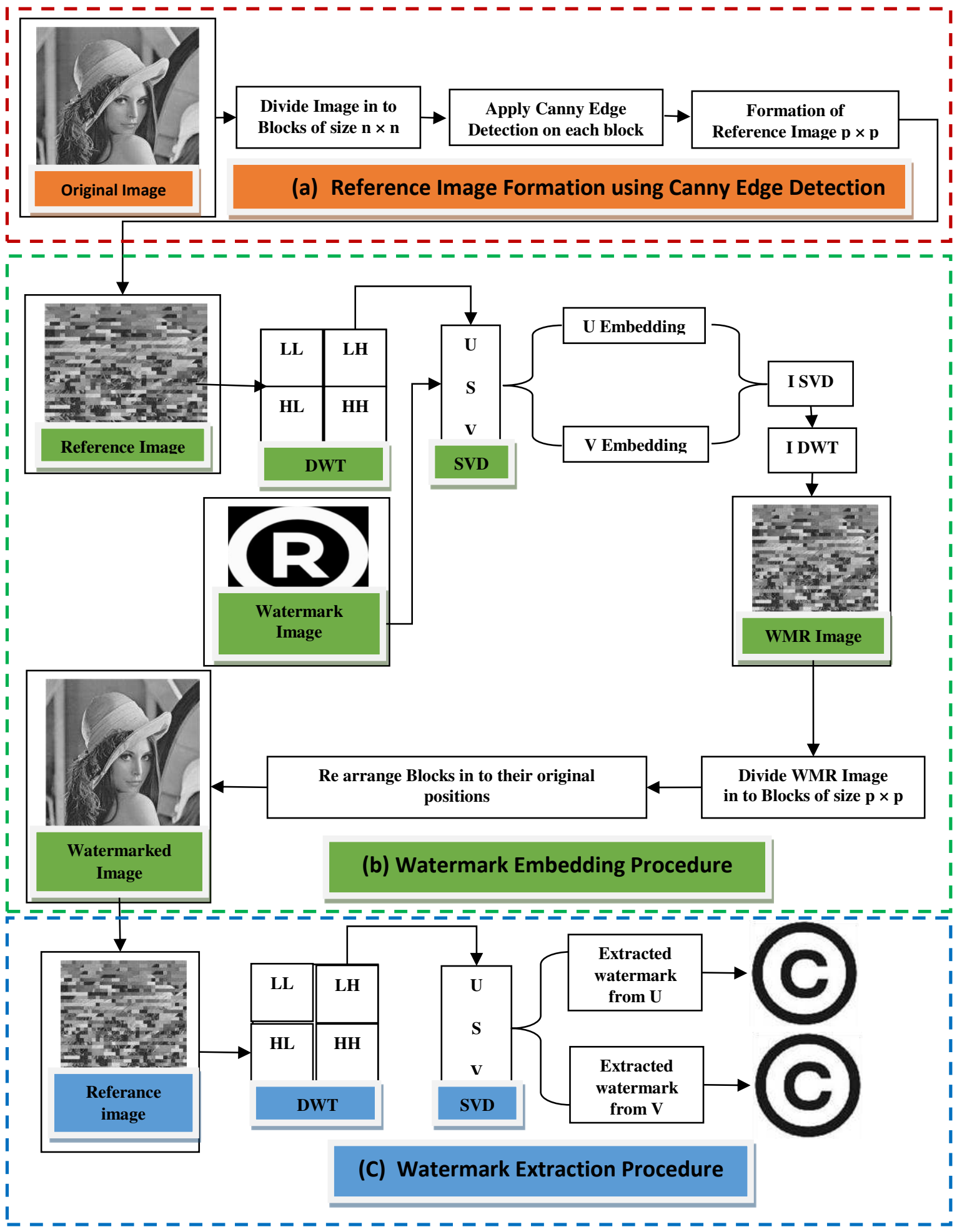

Figure 2: (a) Referance Image formation (b) Watermark Embedding Procedure (c) Watermak Extraction Procedure 
Stage 8: To get the watermarked image, apply the IDWT utilizing the accompanying equation 9 and is shown in fig 2(b).

$W_{w m d}=\left[L L_{r e f}, W_{s v d}, H L_{r e f}, H H_{r e f}, ' h a a r^{\prime}\right]$

\subsection{Watermark Extraction Procedure}

Stage 1: Import the watermarked image $W_{w m d}$

Stage 2: Divide the watermarked image to $n \times n$ blocks.

Stage 3: Identify the essential blocks and form the watermarked reference image

Stage 4: apply DWT to the watermarked reference image, it has given four bands by the following equation 9 ..

$\left[L L_{w m d}, L H_{w m d}, H L_{w m d}, H H_{w m d}\right]=\left(W_{w m d},{ }^{\prime} h a a r^{\prime}\right)$

Stage 5: apply SVD on $L H_{w m d}$ by using the equation 10.

$\left[U_{w m d}, S_{w m d}, V_{w m d}\right]=\operatorname{svd}\left(L H_{w m d}\right)$

Stage 6: Extract U component by the following equation 11.

$$
U_{\text {extract }}=\frac{U_{w m d}-U_{w}}{\beta}
$$

Stage 7: Form the extract watermark from U component by using the following equation 12.

$$
W_{\text {extract } u}=U_{\text {extract }} * S_{w} * V_{w}^{T}
$$

Stage 8: Extract V component by the following equation 13.

$V_{\text {extract }}=\frac{V_{w m d}-V_{w}}{\beta}$

Stage 9: Form the extracted watermark from $\mathrm{V}$ component by using the following equation 14.

$W_{\text {extract } v}=U_{w} * S_{w} * V_{\text {extract }}^{T}$

\section{Results and discussion}

The experimental outcomes of the wished-for method are presented here. Four greyscale images of size 512 × 512 are considered to cover images as shown in figure 3 (a)-(d). The size of the reference image is considered as 256 x 256. The size of the watermark image is considered as 128 $\mathrm{x} 128$ is as indicated in figure 3 (e)-(f). For implanting the watermark into the cover image consider the $64^{\text {th }}$ column of $\mathrm{U}$ component and $64^{\text {th }}$ row of $\mathrm{V}$ component. The $\mathrm{LH}$ band of the reference image is taken to implant a watermark. The watermark significance $\beta$ is taken to insert a watermark in $\mathrm{U}$ and $\mathrm{V}$ component is 0.4 and 0.3 respectively. In general, the basic characteristics of any 
watermarking system are defined through imperceptibility, robustness, security, and payload. The imperceptibility is measured between the original image and watermarked image i.e adding a watermark to the original image. It is measured by equation 15 .

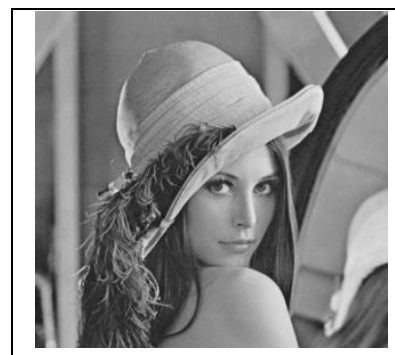

(a)

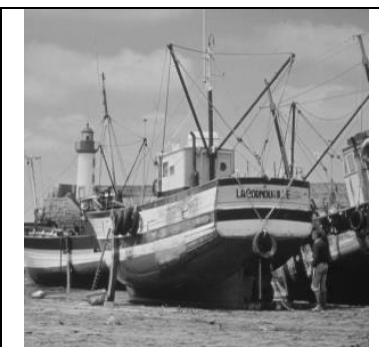

(b)

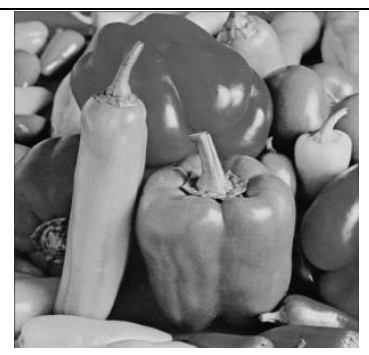

(c)

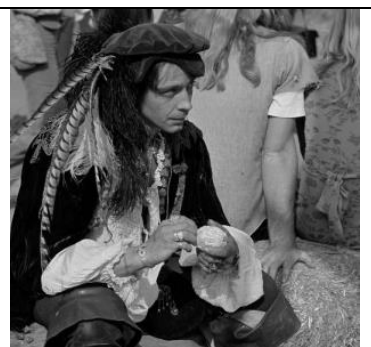

(d)

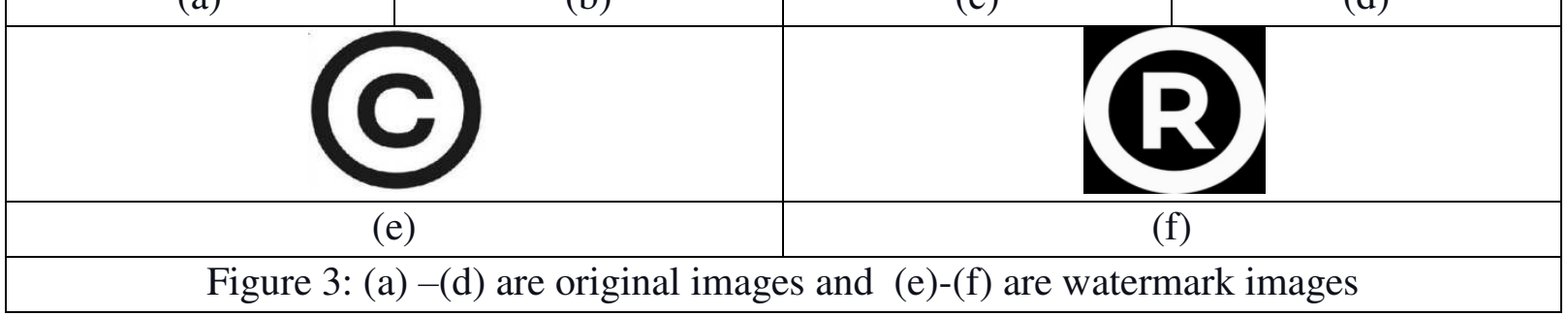

$P S N R=20 \log _{10}\left(\frac{\max }{\sqrt{M S E}}\right) d B$

Where MSE (Mean squared error) is given by equation 16.

$$
M S E=\frac{1}{m n} \sum_{0}^{m-1} \sum_{0}^{n-1}[f(i, j)-g(i, j)]^{2}
$$

' $f$ ' represents the data matrix of the initial file.

' $\mathrm{g}$ ' reflects the corrupted picture matrix data

$\mathrm{m} n$ reflects the dimension of the picture

$(i, j)$ reflects the index of the row and column.

MAX is the most useful signal that exists in the initial "known to be fine" picture. 


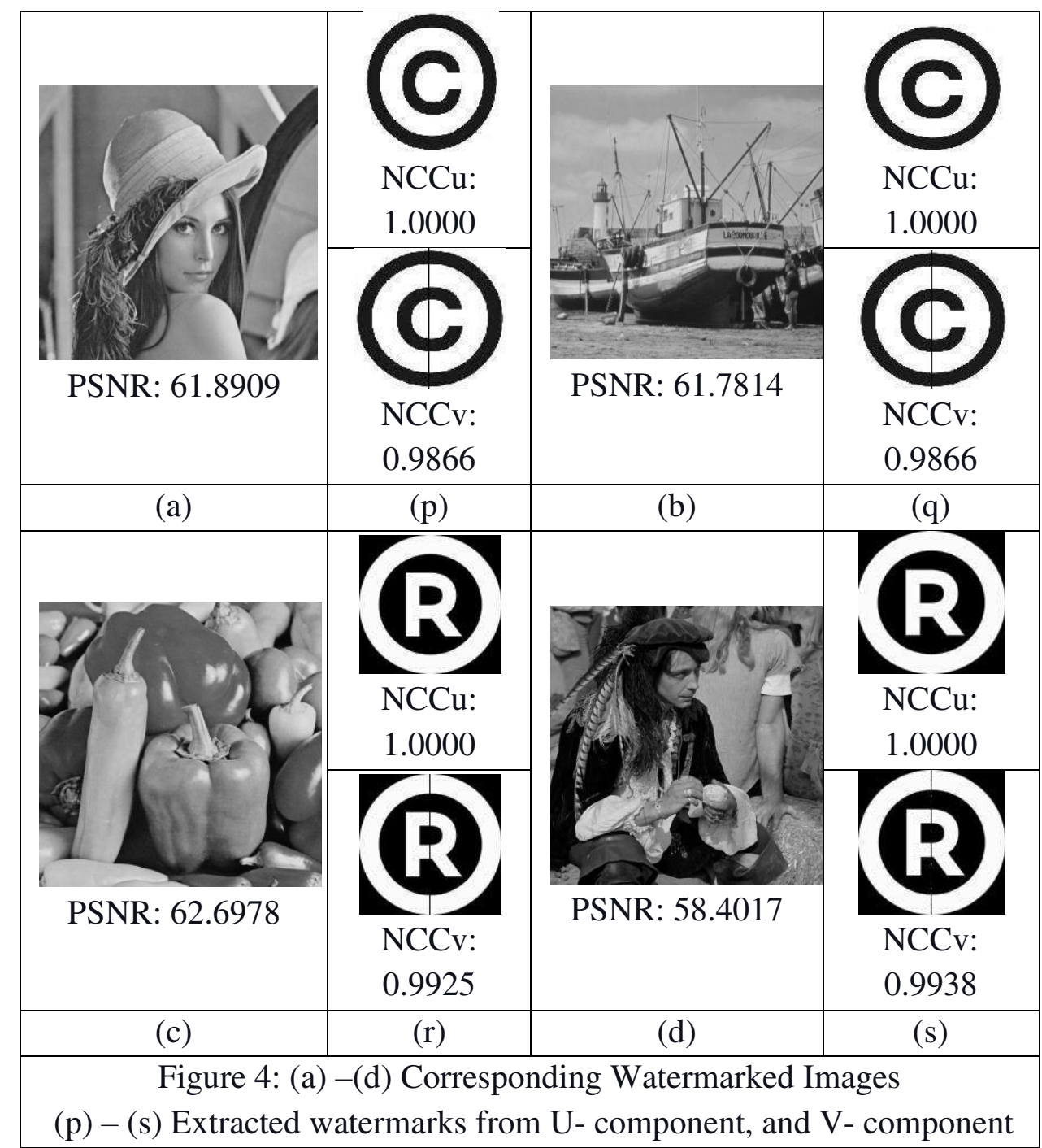

The robustness is measured to check them with stand of the watermark albeit associate offender tries to get rid of the watermark and it's calculated from the subsequent equation 17.

$$
\mathrm{NCC}=\frac{\sum_{\mathrm{m}} \sum_{\mathrm{n}}\left(\mathrm{F}_{\mathrm{mn}}-\overline{\mathrm{F}}\right)\left(\mathrm{G}_{\mathrm{mn}}-\overline{\mathrm{G}}\right)}{\sqrt{\left(\sum_{\mathrm{m}} \sum_{\mathrm{n}}\left(\mathrm{F}_{\mathrm{mn}}-\overline{\mathrm{F}}\right)\right)^{2}\left(\sum_{\mathrm{m}} \sum_{\mathrm{n}}\left(\mathrm{G}_{\mathrm{mn}}-\overline{\mathrm{G}}\right)\right)^{2}}}
$$

Where NCC is the normalized cross-correlation. ' $\mathrm{F}$ ' is the original watermark image. $G$ is the extracted watermark image. $\bar{F}$ Is the mean of original watermark and $\bar{G}$ is the mean of the extracted watermark image. The $\mathrm{m}$ and $\mathrm{n}$ are given as the size of the image.

In fig 4 (a)-(b) is shown that the watermarked images with their debasing values by considering the 'copy' image as a watermark image and the corresponding extract watermark logos from the watermarked images with their NCC values in fig 4 (p) - (q). The same way is shown in fig 4 (c)(d) and fig 4 (r) - (s) with watermark image is 'copyright R'. 


\begin{tabular}{|l|c|c|c|c|}
\hline \multirow{2}{*}{\multicolumn{1}{|c|}{ Table 3: NCC values from Lena and Boat watermarked images without applying any attacks }} \\
\cline { 2 - 5 } & \multicolumn{2}{|c|}{ Lena } & \multicolumn{2}{c|}{ Boat } \\
\cline { 2 - 5 } & $\begin{array}{c}\mathrm{U} \\
\text { Component }\end{array}$ & $\begin{array}{c}\mathrm{V} \\
\text { Component }\end{array}$ & $\begin{array}{c}\mathrm{U} \\
\text { Component }\end{array}$ & $\begin{array}{c}\mathrm{V} \\
\text { Component }\end{array}$ \\
\hline Average Filter (9 x 9) & 0.9995 & 0.9962 & 0.9994 & 0.9866 \\
\hline Median Filter (9 x 9) & 0.9995 & 0.9934 & 0.9996 & 0.9909 \\
\hline Gaussian noise (0.6) & 0.9996 & 0.9855 & 0.9995 & 0.9868 \\
\hline Compression QF = 50 & 0.9995 & 0.9877 & 0.9996 & 0.9894 \\
\hline Rotation $\left(50^{0}\right)$ & 0.9994 & 0.9934 & 0.9995 & 0.9868 \\
\hline Gamma correction 0.6 & 0.9996 & 0.9957 & 0.9996 & 0.9975 \\
\hline Cropping (25\% area remaining) & 0.9995 & 0.9936 & 0.9996 & 0.9866 \\
\hline Resizing (512 -> 64 -> 512) & 0.9995 & 0.9820 & 0.9996 & 0.9872 \\
\hline Histogram Equalization & 0.9996 & 0.9850 & 0.9996 & 0.9835 \\
\hline Sharpening(80) & 0.9995 & 0.9861 & 0.9995 & 0.9934 \\
\hline
\end{tabular}

An attack is a process to remove a watermark from a watermarked image. The proposed watermarking scheme is tested against numerous attacks such as average filtering, median filtering, Gaussian filtering, and compression of the image, sharpening, rotating, cropping, resizing, and equalization of histograms. The corresponding experimental results are tabulated in table 3 and test images are Lena and Boat images. In table 4 the experimental results for test images Peppers and Pirate are shown. The detailed descriptions of all the attacks are given in the following discussion.

\begin{tabular}{|l|c|c|c|c|}
\hline \multirow{2}{*}{\multicolumn{1}{|c|}{ Table 4: NCC values from Peppers and Pirate watermarked images without applying any attacks }} \\
\cline { 2 - 5 } & \multicolumn{2}{c|}{ Peppers } & \multicolumn{2}{c|}{ Pirate } \\
\cline { 2 - 5 } & $\begin{array}{c}\mathrm{U} \\
\text { Component }\end{array}$ & $\begin{array}{c}\mathrm{V} \\
\text { Component }\end{array}$ & $\begin{array}{c}\mathrm{U} \\
\text { Component }\end{array}$ & $\begin{array}{c}\mathrm{V} \\
\text { Component }\end{array}$ \\
\hline Average Filter (9 x 9) & 0.9999 & 0.9962 & 0.9999 & 0.9945 \\
\hline Median Filter (9 x 9) & 1.0000 & 0.9990 & 0.9999 & 0.9943 \\
\hline Gaussian noise (0.6) & 1.0000 & 0.9945 & 1.0000 & 0.9923 \\
\hline Compression QF = 50 & 1.0000 & 0.9960 & 0.9999 & 0.9999 \\
\hline Rotation (50 $)$ & 0.9999 & 0.9979 & 0.9999 & 0.9929 \\
\hline Gamma correction 0.6 & 0.9999 & 0.9957 & 0.9999 & 0.9975 \\
\hline Cropping (25\% area remaining) & 0.9999 & 0.9982 & 0.9999 & 0.9978 \\
\hline Resizing (512 -> 64 -> 512) & 1.0000 & 0.9957 & 1.0000 & 0.9947 \\
\hline Histogram Equalization & 0.9999 & 0.9965 & 0.9999 & 0.9965 \\
\hline Sharpening(80) & 1.0000 & 0.9997 & 1.0000 & 0.9926 \\
\hline
\end{tabular}

The most widely recognized manipulation in a digital image is filtering. The separated watermarks from watermarked images, subsequent to applying $9 \times 9$ averaging and median filtering, are appeared in Figs. 5 and 6 with corresponding NCC values. It very well may be seen that after applying these attacks, images are a lot of corrupted and a great deal of information is lost yet the separated logo watermark is as yet unmistakable. 


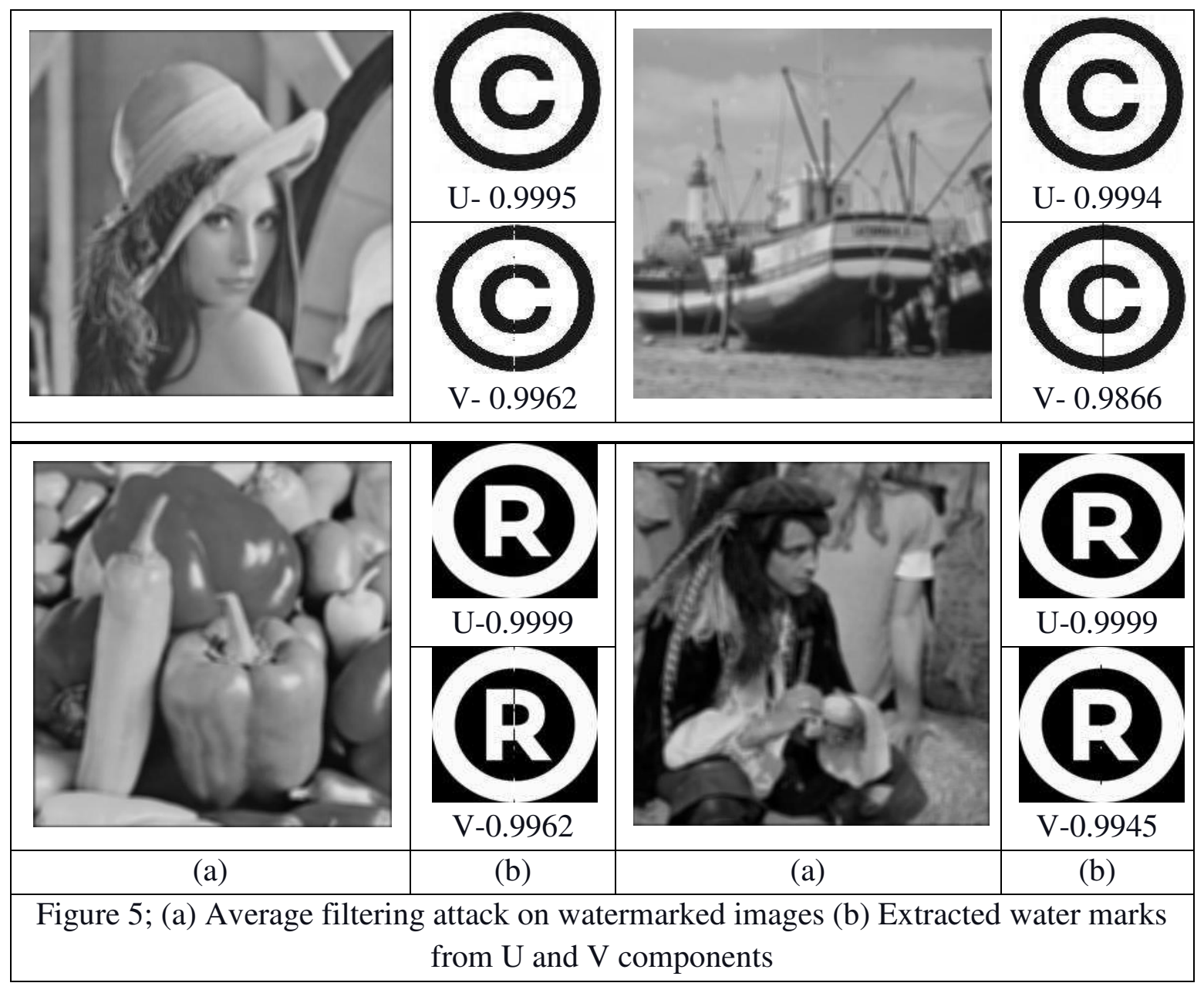




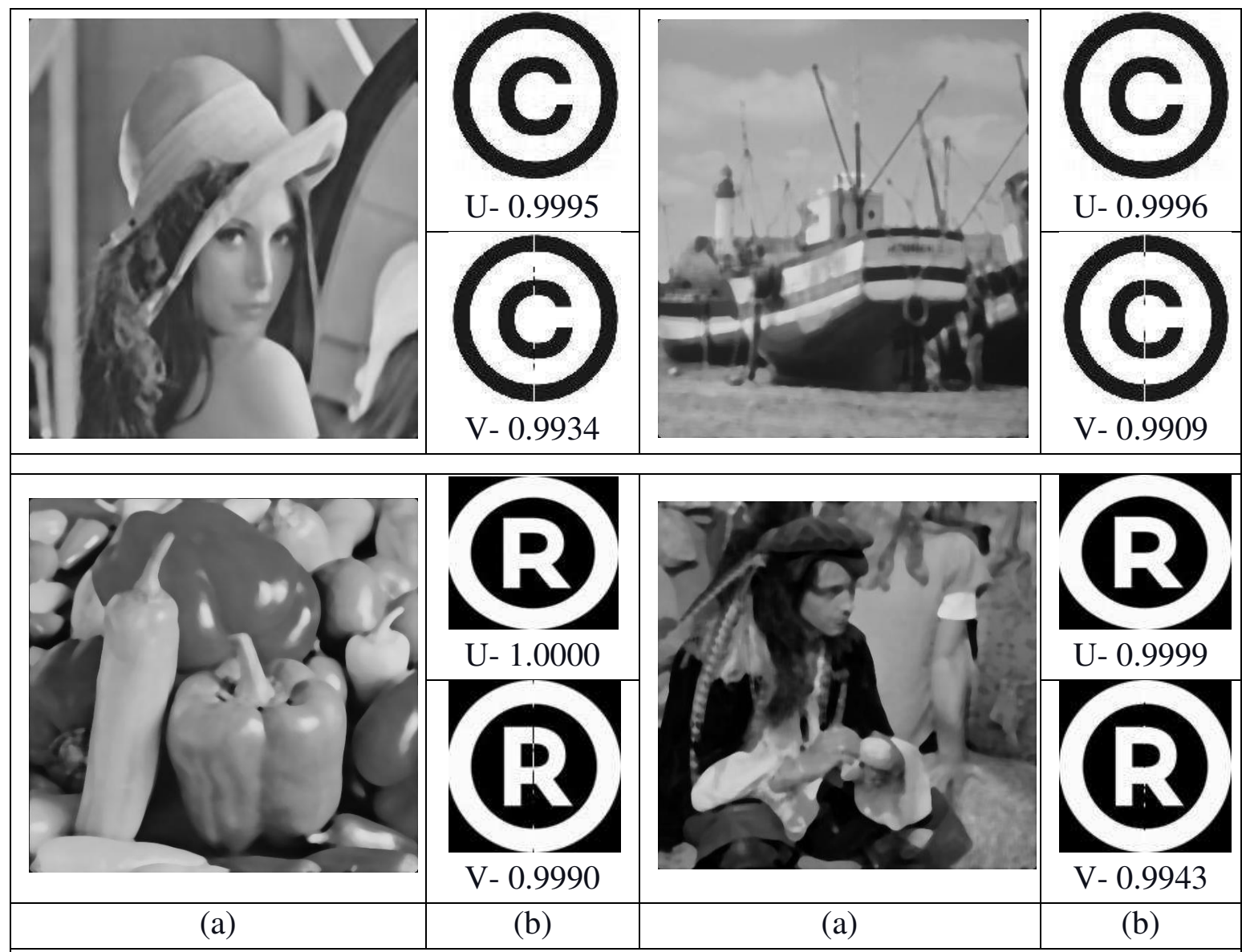

Figure 6: (a) Median filtering attack on watermarked images (b) Extracted water marks from $\mathrm{U}$ and $\mathrm{V}$ components 

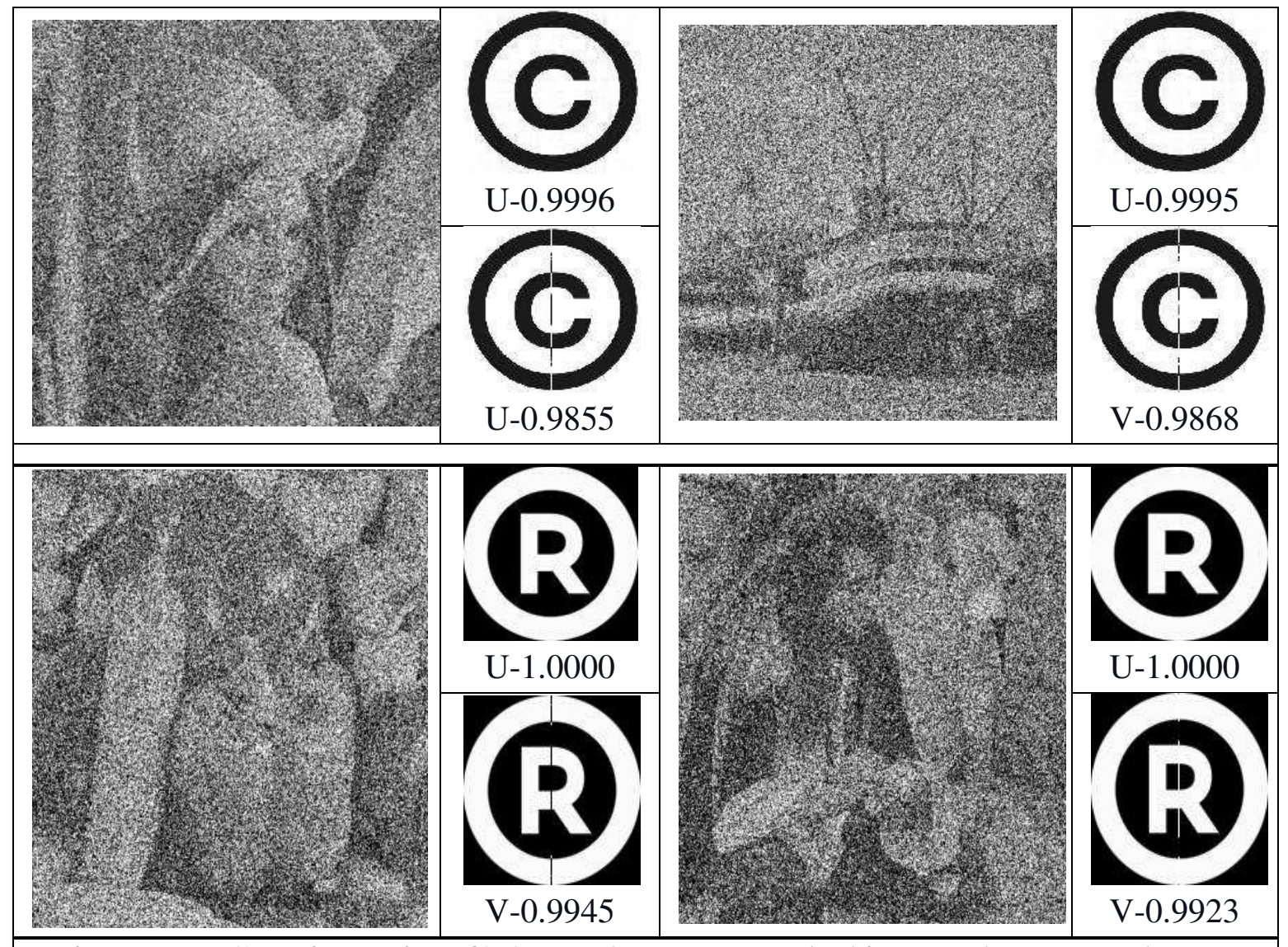

Figure 7: (a)Gaussian Noise (60\%) attack on watermarked images (b) Extracted water marks from $\mathrm{U}$ and $\mathrm{V}$ components 


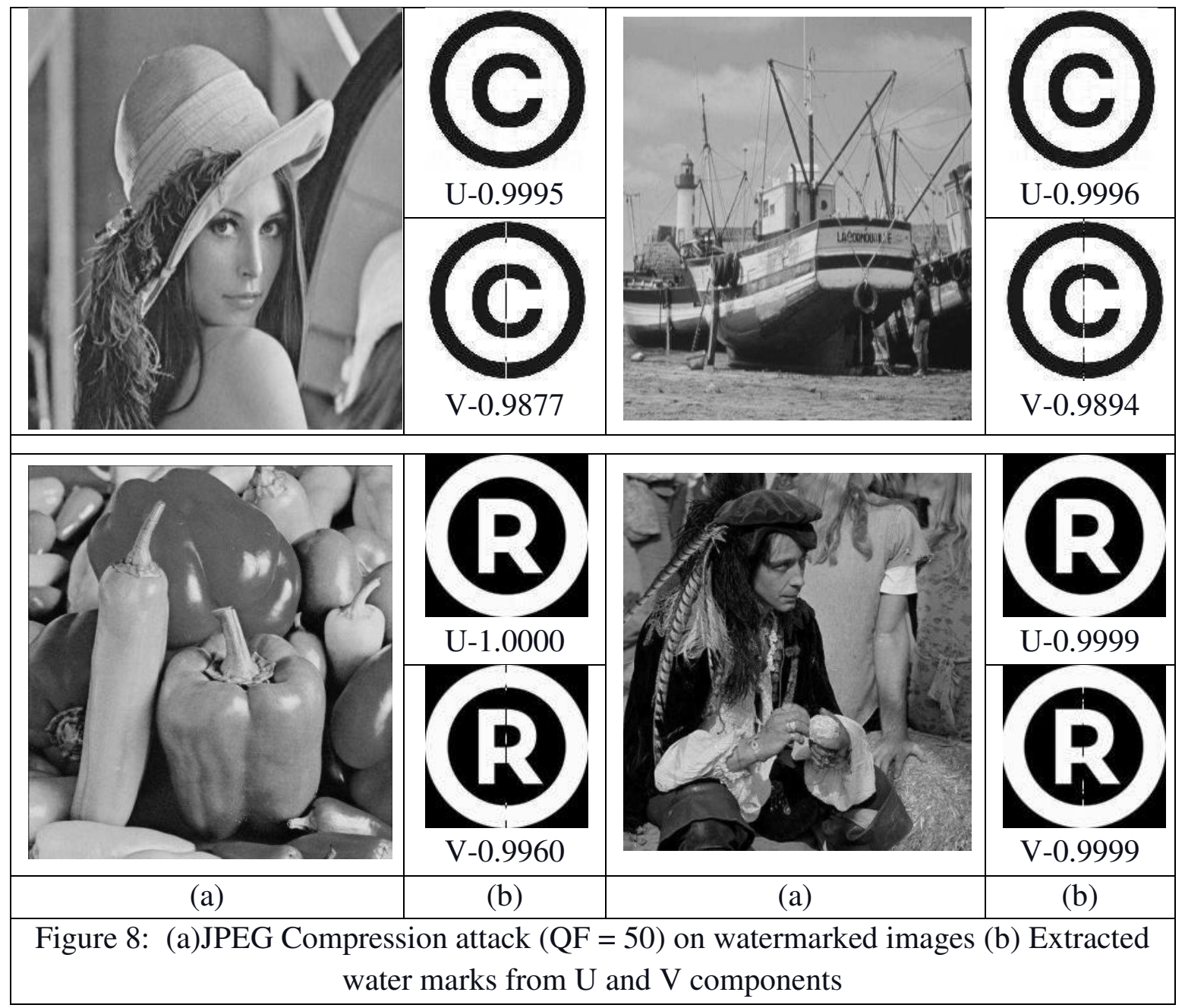




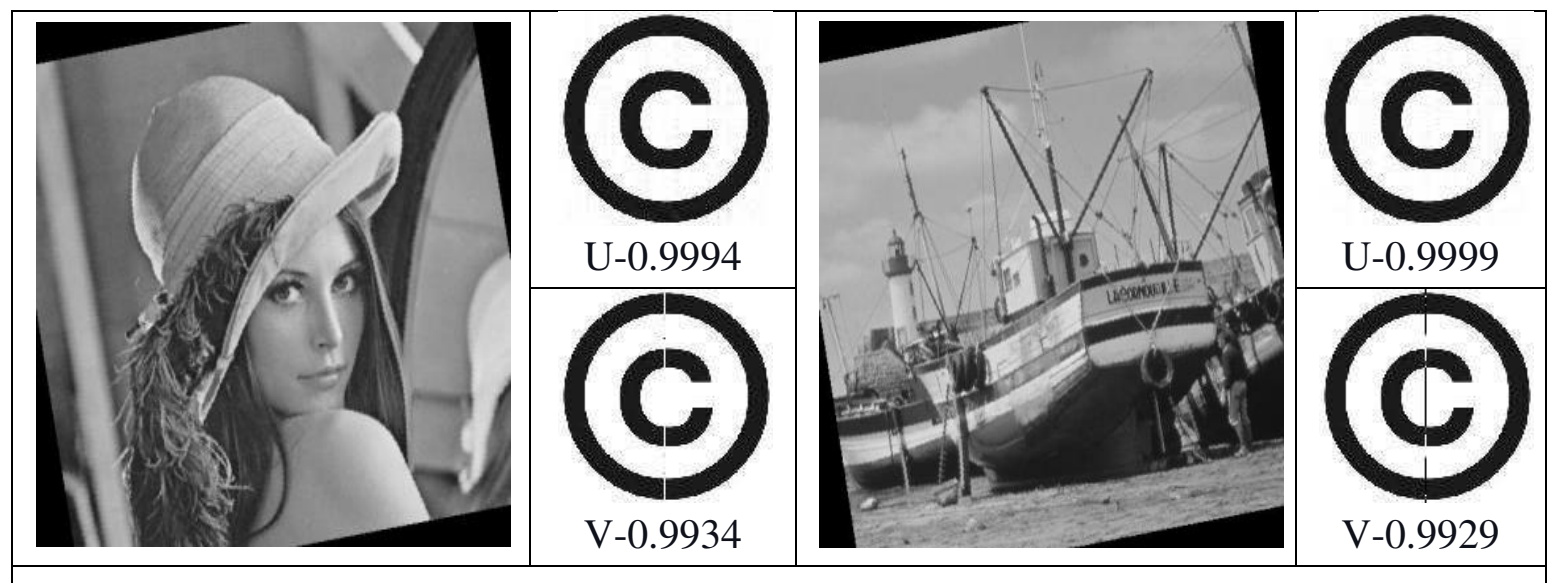

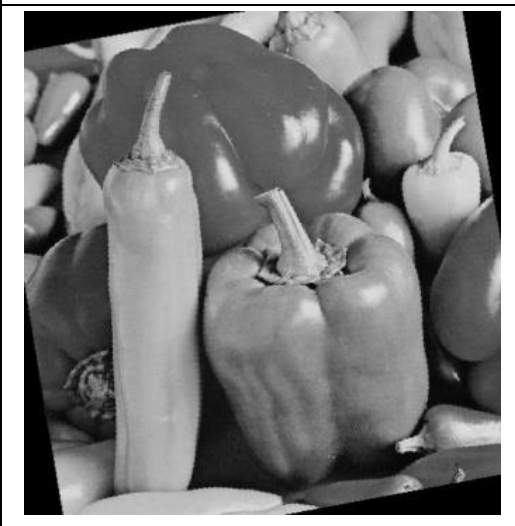

(a)

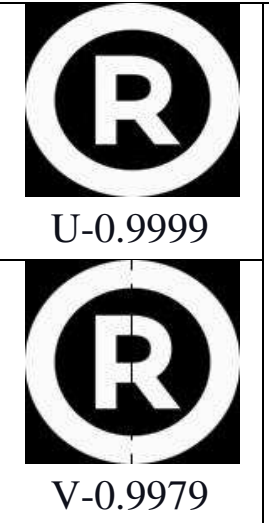

(b)

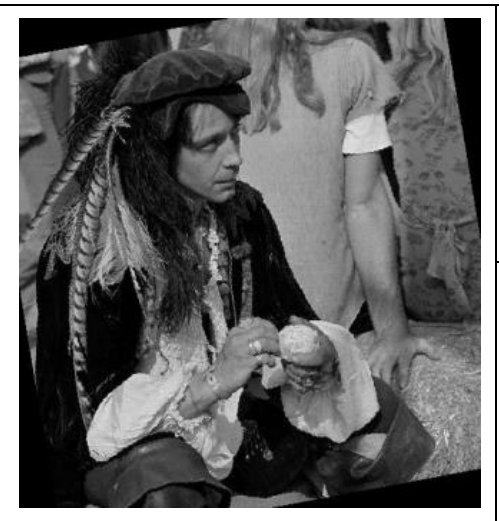

(a)

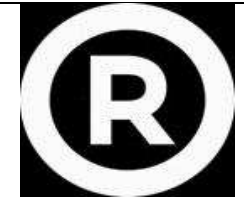

U-0.9999

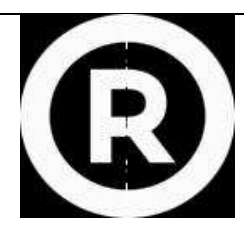

V-0.9929

(b)

Figure 9: (a)Rotation attack $\left(10^{0}\right)$ on watermarked images (b) Extracted water marks from $\mathrm{U}$ and $\mathrm{V}$ components 


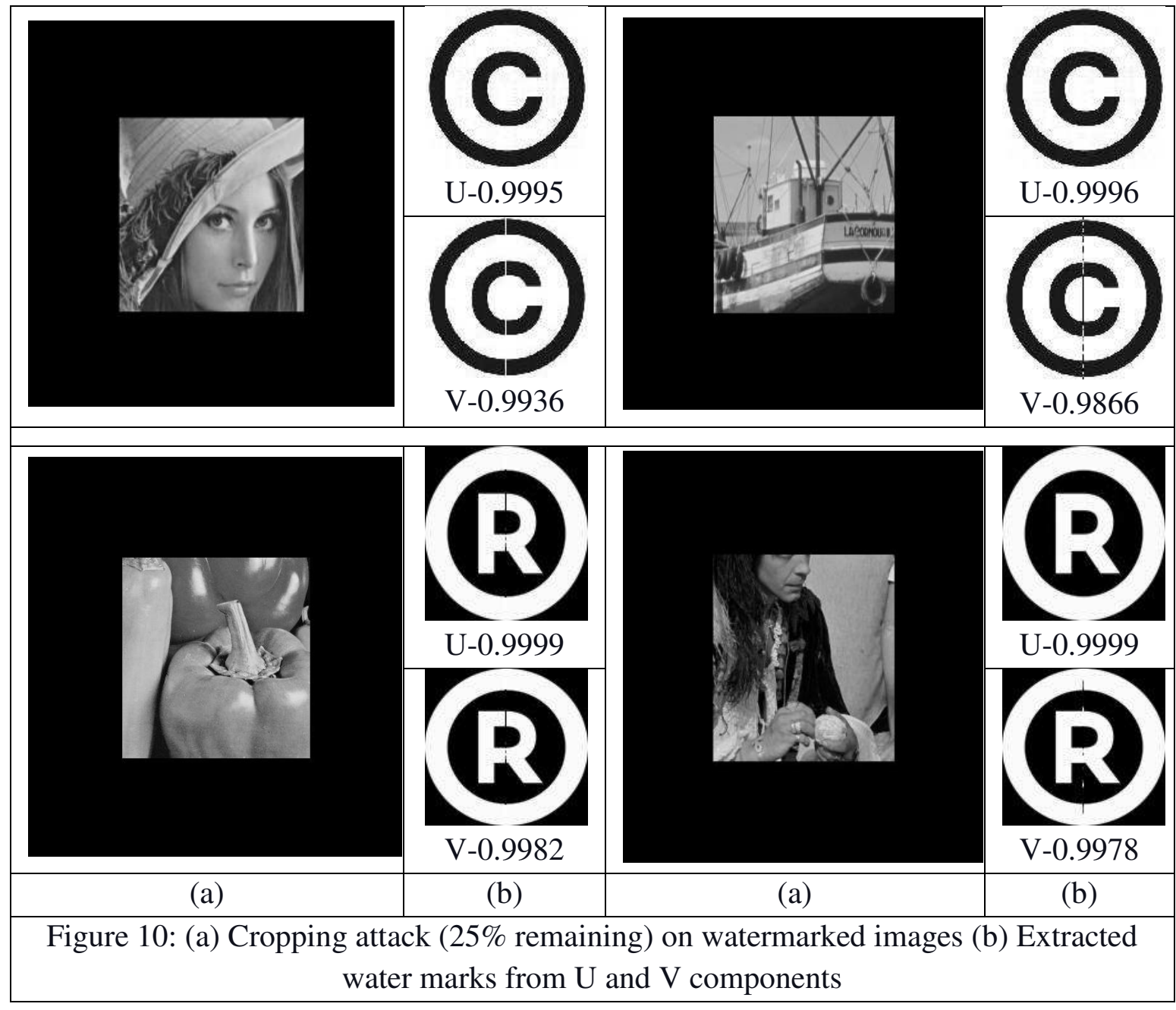




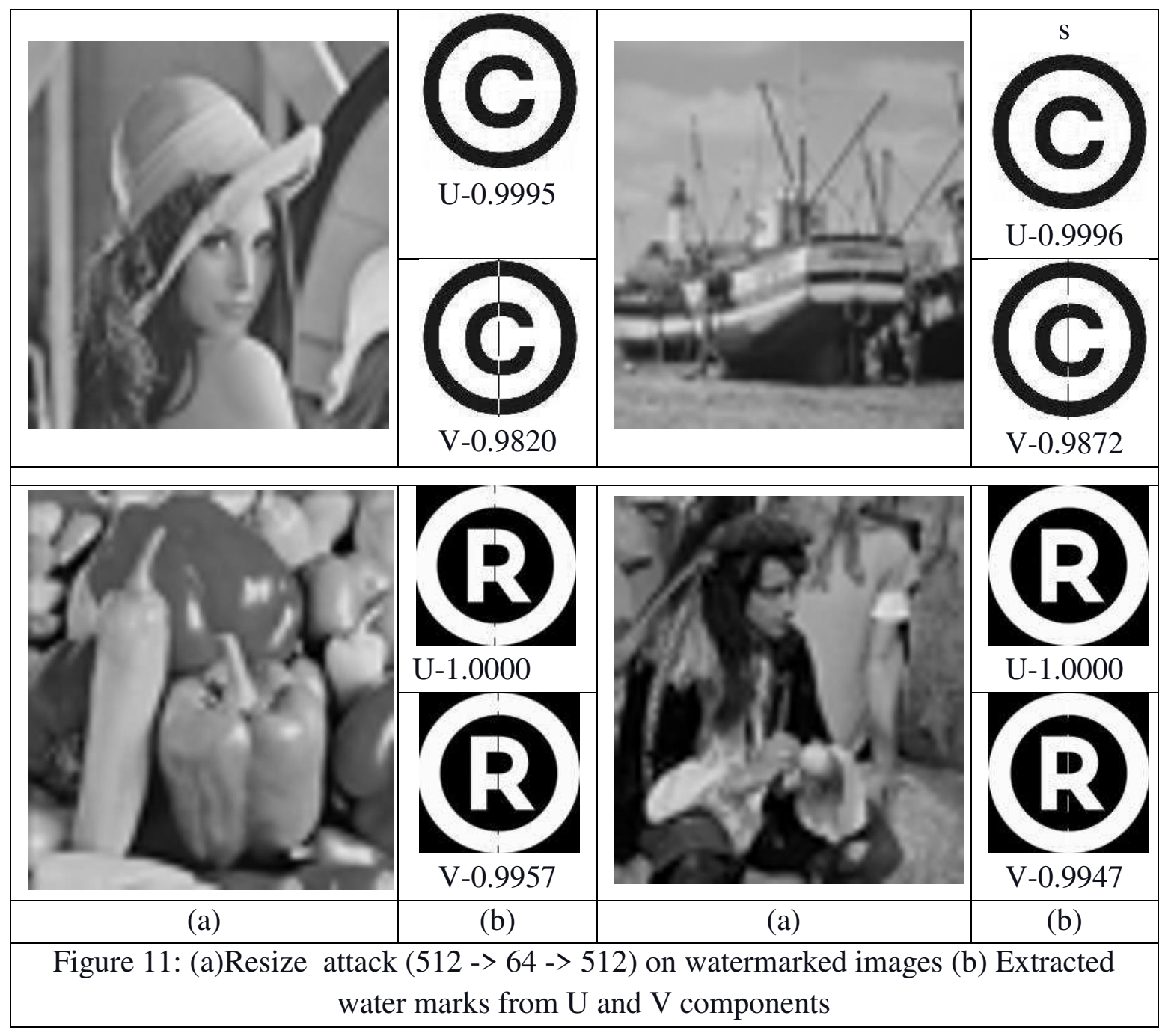



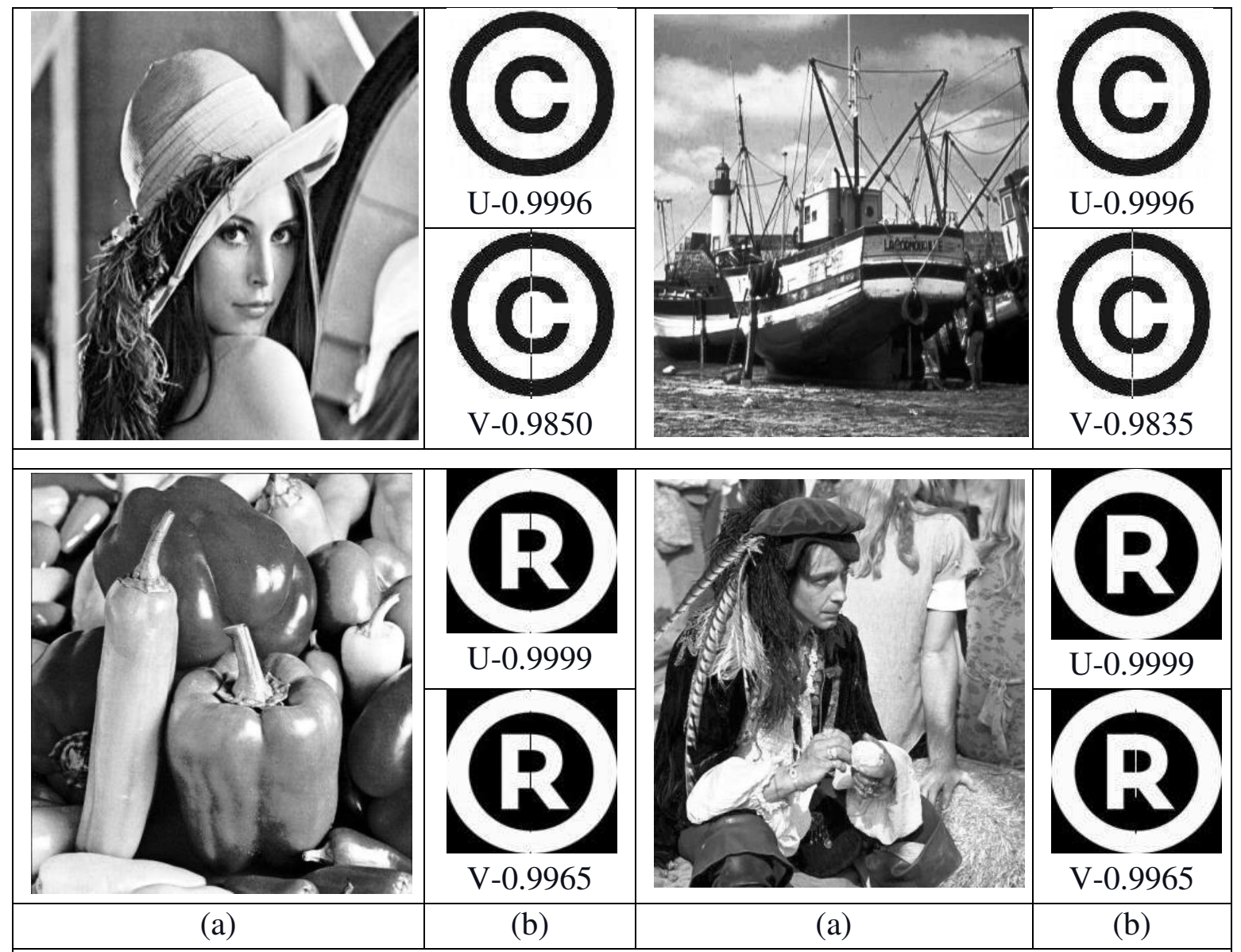

Figure 12: (a)Histogram Equalization attack on watermarked images (b) Extracted watermarks from $\mathrm{U}$ and $\mathrm{V}$ components 

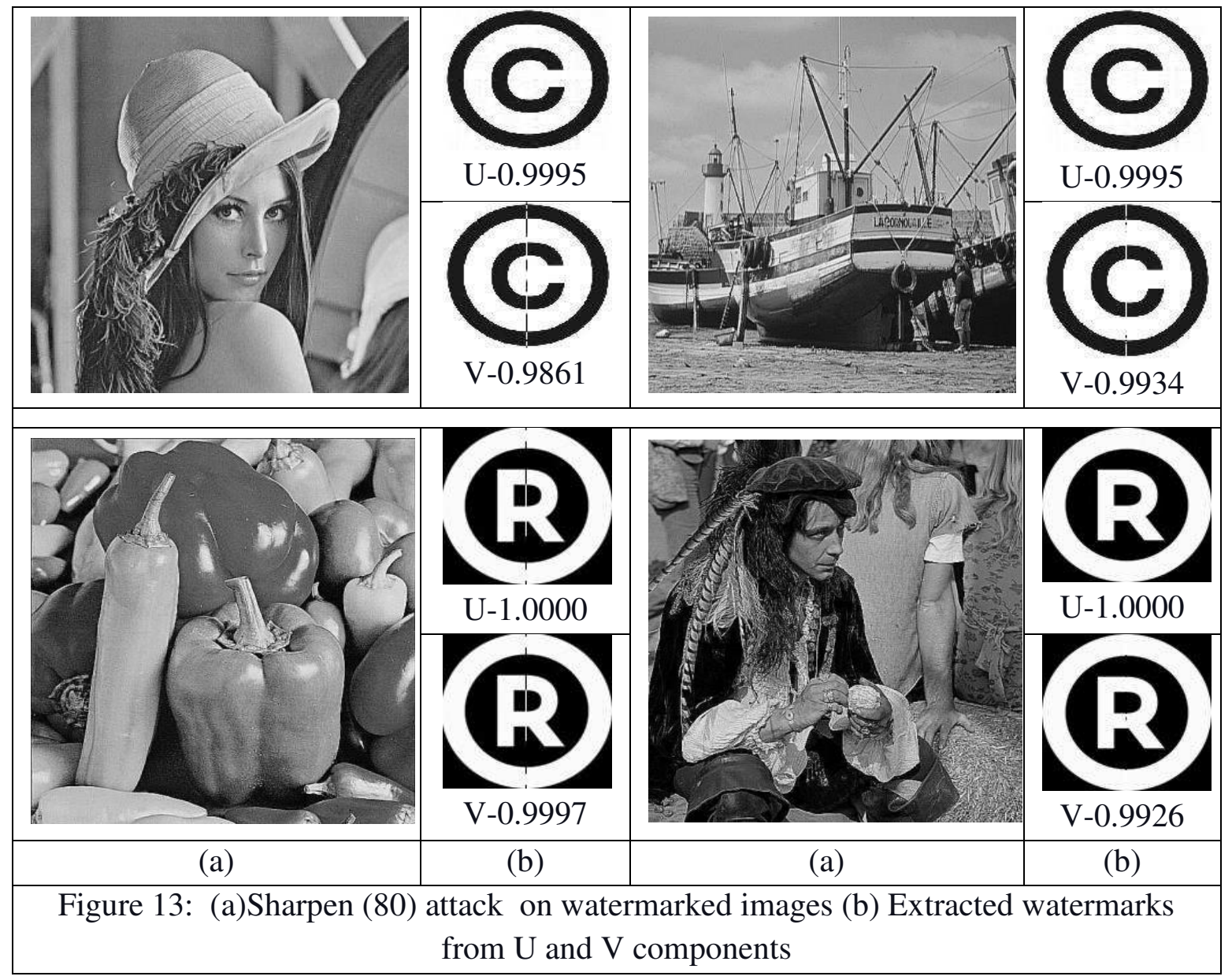

The addition of noise is another strategy to assess the vigour of the watermark. The watermarked data is debased by the addition of noise and results in trouble to watermark extraction. Force against included substance upheaval is surveyed by debasing the watermark image by heedlessly including 60\% Gaussian noise. The expelled logos have shown up in Fig. 7 (b) - (d) with their NCC values and it might be seen that the extracted logo is an uproarious image, anyway obvious.

Perhaps the most common distortion of a computerized image is JPEG compression. To test the force against image compression, a watermarked image is tried with a JPEG compression attack. The independent watermark logo of the compressed image 50:1 has been displayed in fig 8 (b) (d) with their NCC values. 
From the writing, we realize that the wavelet change isn't rotationally invariant. The proposed strategy can remove watermarks for adequately huge pivots. We separated the watermark from a $50^{\circ}$ rotated watermarked image. The outcome has appeared in fig $9(\mathrm{~b})-(\mathrm{d})$ with their NCC values.

Image cropping is much of the time utilized, all things considered. Analysis refers to the process by which a portion of an image is extracted and expelled to make the core or to enhance its synthesis. Finishing the cropping of an image by either covering up or erasing lines or parts. This is more of a failed operation. For this attack, $3 / 4^{\text {th }}$ of the watermarked picture is cropped and then the watermark is split and seen in fig 10 (b) - (d) with their NCC values. To fit the image into the ideal size, augmentation or decrease is regularly performed and brought about data loss of the image including the installed watermark. For this attack, first, the size of the watermarked image is decreased to $64 \times 64$ and again brought to its unique size $512 \times 512$. The removed watermark logo has appeared in fig $11(\mathrm{~b})-(\mathrm{d})$.

We additionally tried our proposed watermarking technique for histogram equalization and sharpen as a general image preparing attacks. Fig 12 (b) - (d) show the results of the extracted watermark logo for Histogram Equalization. For sharpen attack, the sharpness of the watermarked image is expanded by a factor of 80 . Fig $(b)-(d)$ indicated that the results are almost missing but we are also able to identify the watermark.

\begin{tabular}{|l|c|c|c|c|c|c|c|}
\hline \multicolumn{7}{|c|}{ Table 5: NCC values from contrasted to other related current approaches } \\
\hline \multirow{2}{*}{ Attacks } & $\begin{array}{c}\text { D. Rajani } \\
\text { et al. } \\
\text { scheme } \\
{[27]}\end{array}$ & $\begin{array}{c}\text { E. } \\
\text { Najafia } \\
\text { et al } \\
{[26]}\end{array}$ & $\begin{array}{c}\text { Ali et } \\
\text { al. } \\
\text { scheme } \\
{[24]}\end{array}$ & $\begin{array}{c}\text { Makbol } \\
\text { et al } \\
\text { scheme } \\
{[23]}\end{array}$ & $\begin{array}{c}\text { Ali } \\
\text { Fatahbe } \\
\text { ygi et al } \\
{[25]}\end{array}$ & $\begin{array}{c}\text { Rawat et } \\
\text { al. scheme } \\
{[29]}\end{array}$ & $\begin{array}{c}\text { Proposed } \\
\text { Method }\end{array}$ \\
\hline JPEG Compression QF = 50 & 0.9900 & 0.9932 & 0.9985 & 0.9858 & 0.9994 & 0.9960 & $\mathbf{1 . 0 0 0 0}$ \\
\hline Average Filter (9 $\times$ 9) & ---- & --- & 0.9910 & 0.9538 & 0.9965 & 0.9752 & $\mathbf{0 . 9 9 9 9}$ \\
\hline Median Filter $(9 \times$ 9) & 0.9900 & 0.9910 & 0.9953 & 0.9687 & 0.9933 & 0.9812 & $\mathbf{1 . 0 0 0 0}$ \\
\hline Gamma Correction 0.6 & ----- & ---- & 0.9862 & 0.9586 & 0.9966 & 0.9751 & $\mathbf{0 . 9 9 9 9}$ \\
\hline Histogram Equalization & 0.9910 & 0.9932 & 0.9822 & 0.9076 & 0.9823 & 0.9307 & $\mathbf{0 . 9 9 9 9}$ \\
\hline Gaussian noise $(0.6)$ & 0.9901 & 0.9564 & 0.9983 & 0.9055 & 0.9952 & 0.9656 & $\mathbf{1 . 0 0 0 0}$ \\
\hline Resizing $(512->$ 64 -> 512) & 0.9901 & 0.9879 & 0.9978 & 0.9459 & 0.9992 & 0.9912 & $\mathbf{1 . 0 0 0 0}$ \\
\hline Rotation $\left(10^{0}\right)$ & ---- & 0.9905 & 1.0000 & 0.9825 & 0.9104 & 0.8892 & $\mathbf{0 . 9 9 9 9}$ \\
\hline Rotation $\left(-50^{0}\right)$ & 0.9900 & --- & ---- & --- & --- & --- & $\mathbf{0 . 9 9 9 9}$ \\
\hline Sharpening $(80)$ & 0.9901 & 0.9928 & 0.9979 & 0.9887 & 0.9972 & 0.9948 & $\mathbf{1 . 0 0 0 0}$ \\
\hline
\end{tabular}

The suggested algorithm is contrasted to other related current approaches and the findings are seen in Table 5. Our proposed technique is quite versatile against all the attacks as seen by the results achieved.

\section{Conclusions}

Throughout this study, we aim to project a framework for digital visual information authentication assisted by DWT-SVD with human visual characteristics as a novel innovation that has never been created in a particular area. To prevent a false positive SVD problem, according to the SVD function that essentially reflects the inherent algebraic properties of the image, the watermark 
image is placed in column $\mathrm{U}$ or row $\mathrm{V}$. As our experimental findings indicate, there is a decreased inconsistency between imperceptibility and robustness. The experimental findings reveal that the proposed scheme succeeds in rendering the watermark perceptually invisible and even resilient to different signal processing operations and geometric assaults, and also the proposed scheme is compared with other similar schemes and outperforms our scheme. Therefore, we conclude that the new proposed scheme is more suitable to protect the digital visual content copyright that will be transmitted on the Internet.

\begin{abstract}
Abbreviation
DWT: Discrete Wavelet Transform, SVD: Singular Value Decomposition, PSNR: Peak Signal to Noise Ratio, NCC: Normalized Cross Correlation.

Acknowledgements

NA

Authors' contributions

Our contributions in this paper were that the first author (SP) participated in the designing of the scheme, carried out the experiments. The second author (APR) participated in the designing of the scheme. All authors read and approved the final manuscript.

Authors' information

Dr. Satyanarayana Murty. $\mathbf{P}$ has more than 24 years of teaching and research experience. He obtained his Master's degree from JNTU, Hyderabad and Ph.D. from Andhra University, Visakhapatnam. He is presently working as professor of Electronics and Communication Engineering at Vignana's Institute of Information and Technology, Visakhapatnam. He is a member of IETE, ISTE. He guided more than 35 PG students and guiding one Research scholar. His areas of interest are VLSI, DIP, and Embedded Systems. He has 42 publications in international journals and 3 in international conferences

Dr. Addanki Purna Ramesh has more than 24 years of teaching and research experience. He obtained his Master's degree from JNTU, Hyderabad and Ph.D. from JNTUK, Kakinada. He is presently working as professor of Electronics and Communication Engineering at Vishnu Institute of Technology, Bhimavaram. He is a member of IEEE, ACEEE, Institute of Engineers (India), Fellow of Institution of Electronics and Communication Engineers (IETE). His areas of interest are VLSI, DIP, and Embedded Systems. He has 34 publications in international journals and 3 in international conferences

Funding

No funding is provided.
\end{abstract}

Availability of data and materials

Available on internet

Competing interests

The authors declare that they have no competing interests. 
Author details

Corresponding Author and 1st Author

Satyanarayana Murthy.P

Professor

Department of ECE

Vignan Institute of Information and Technology

Duvvada

Visakhspatnam (dt)

Andhra Pradesh

India

Psn,murty71@gmail.com

$2^{\text {nd }}$ Author

Dr. Addanki Purna Ramesh

Professor

Department of ECE

Vishnu Institute of Technology

Bhimavaram,

West Godavari (Dt)

Andhra Pradesh

India

purnarameshaddanki@gmail.com 
Figures

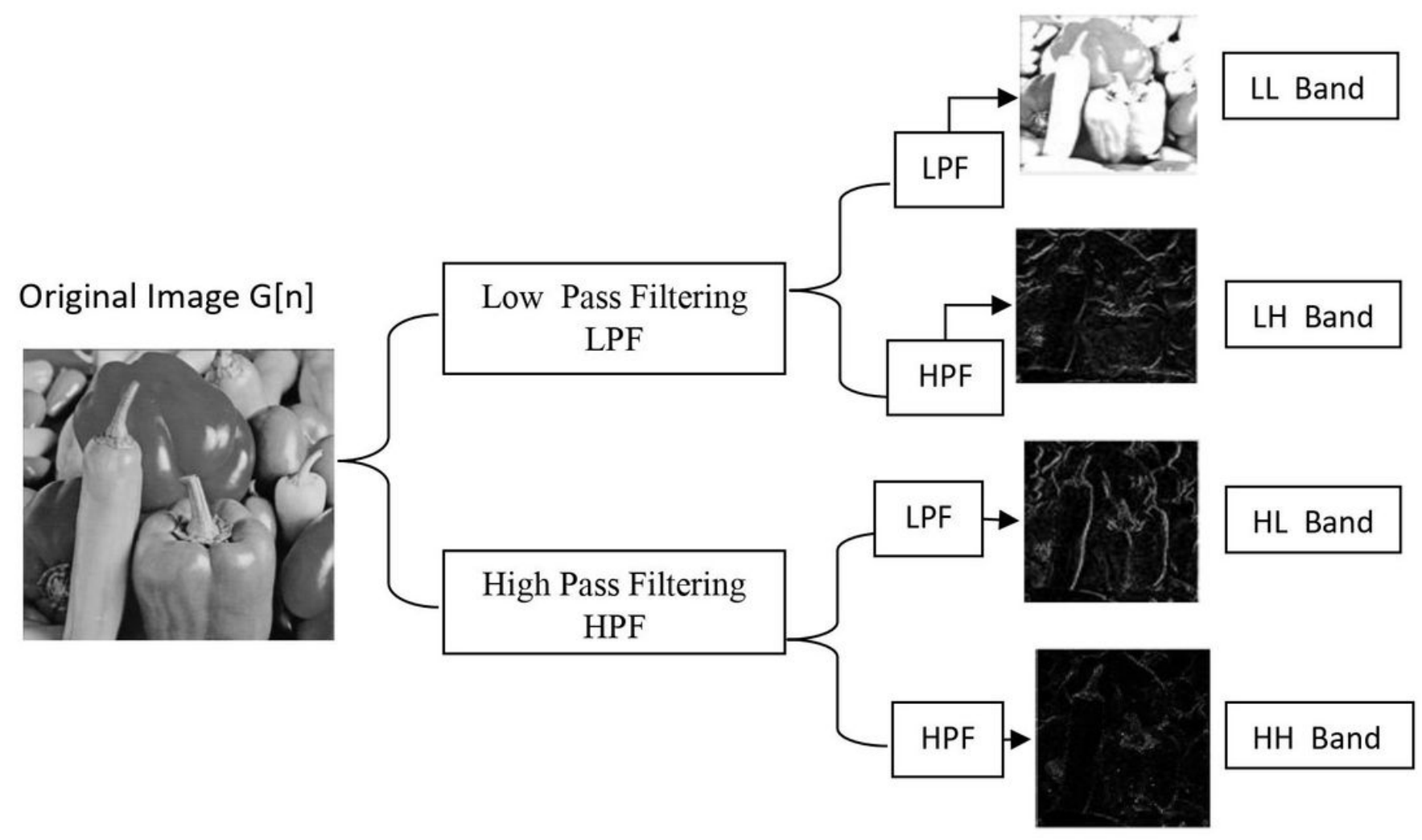

Figure 1

Decomposition of cover image By DWT 


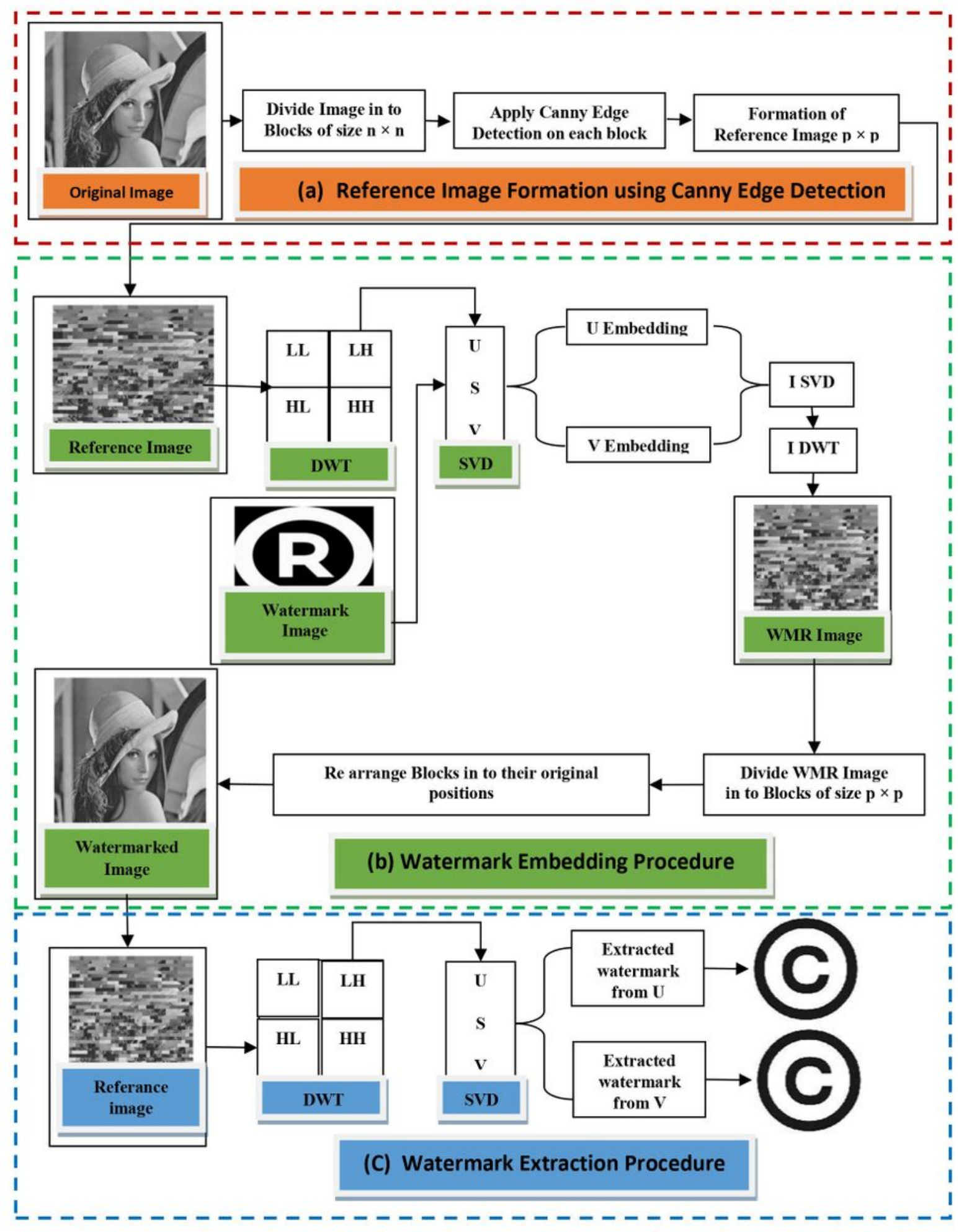

Figure 2

(a) Referance Image formation (b) Watermark Embedding Procedure (c) Watermak Extraction Procedure 


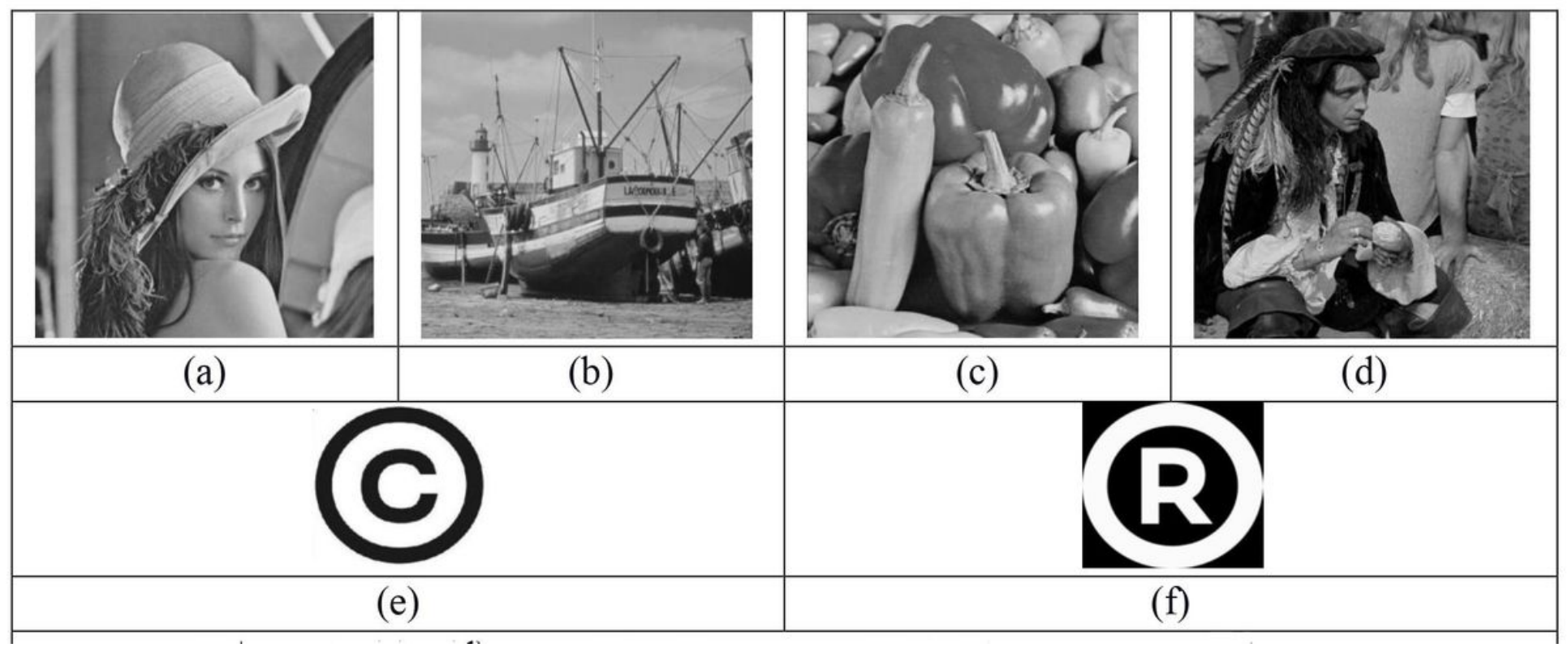

Figure 3

(a) $-(d)$ are original images and (e)-(f) are watermark images 


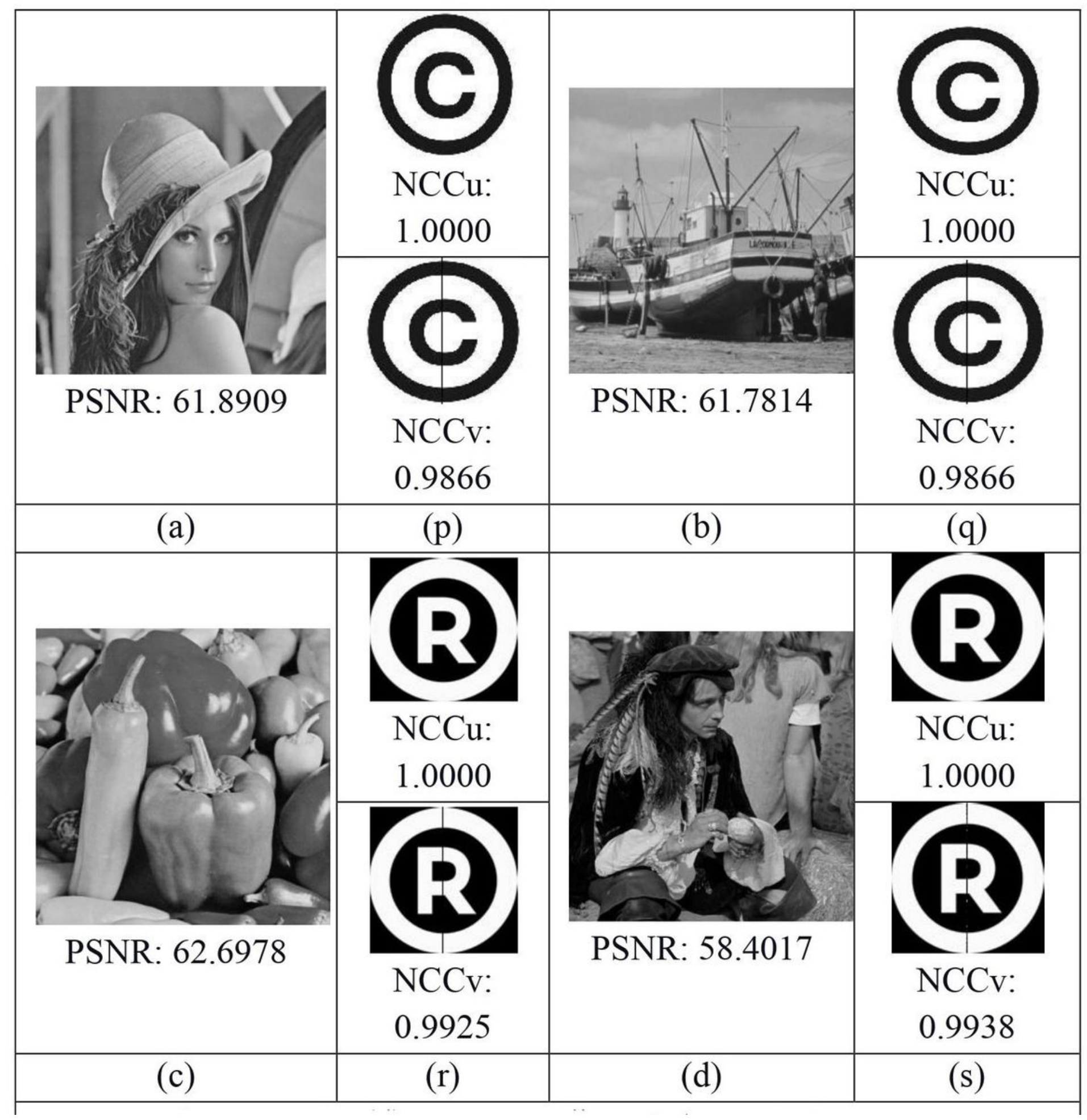

Figure 4

(a) - (d) Corresponding Watermarked Images (p) - (s) Extracted watermarks from U- component, and Vcomponent 


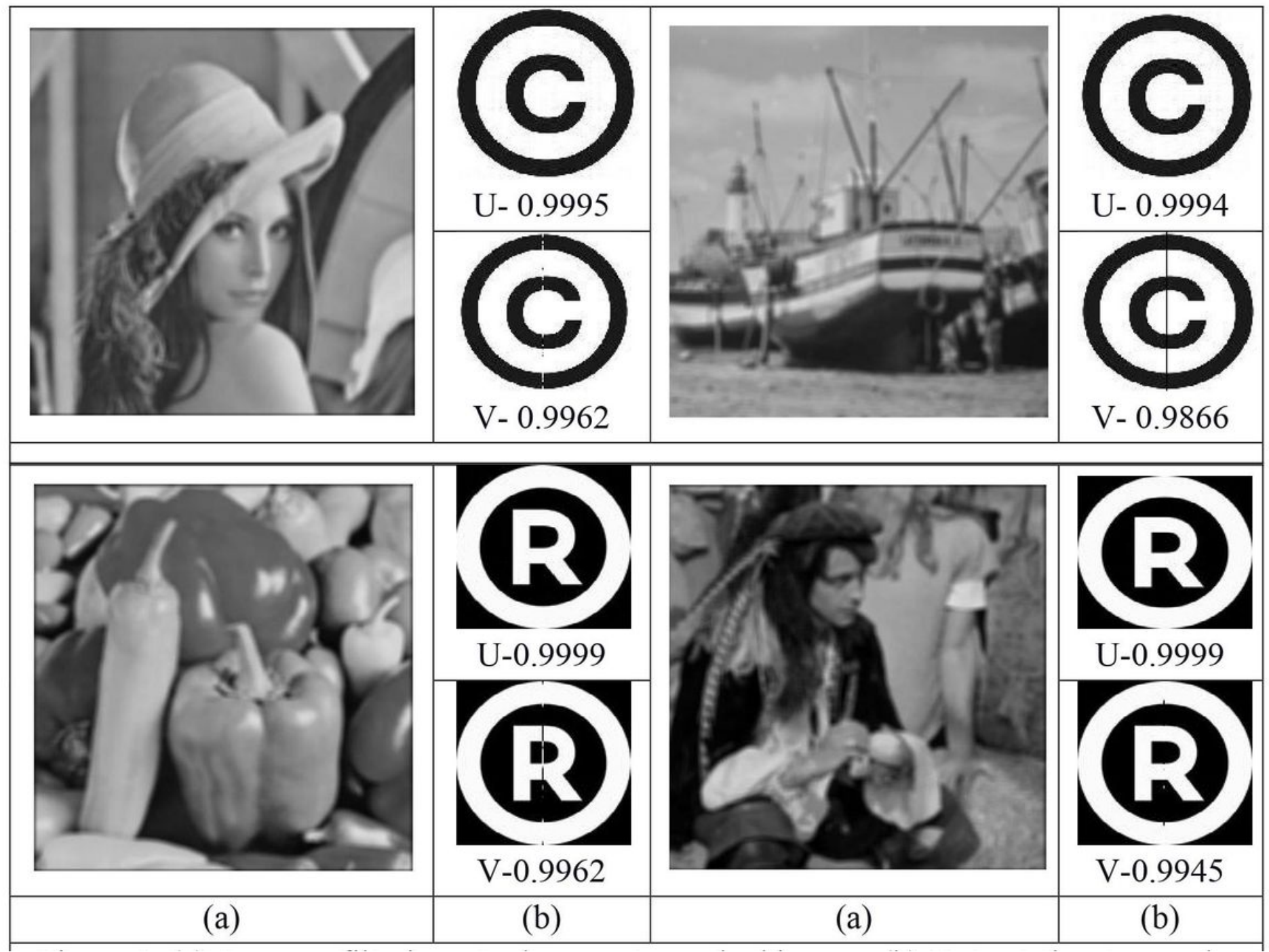

Figure 5

(a) Average filtering attack on watermarked images (b) Extracted water marks from $\mathrm{U}$ and $\mathrm{V}$ components 


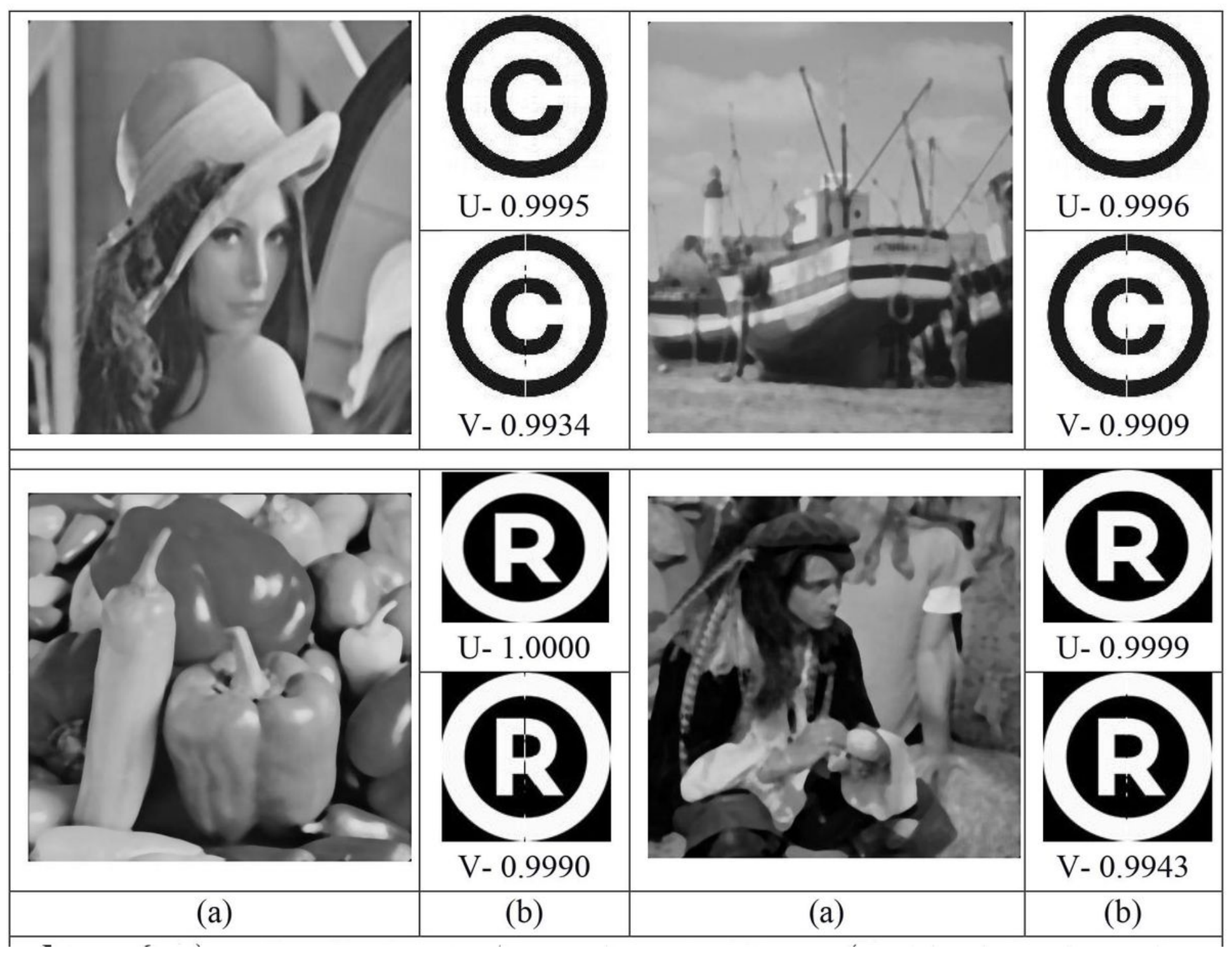

Figure 6

(a) Median filtering attack on watermarked images (b) Extracted water marks from $\mathrm{U}$ and $\mathrm{V}$ components 


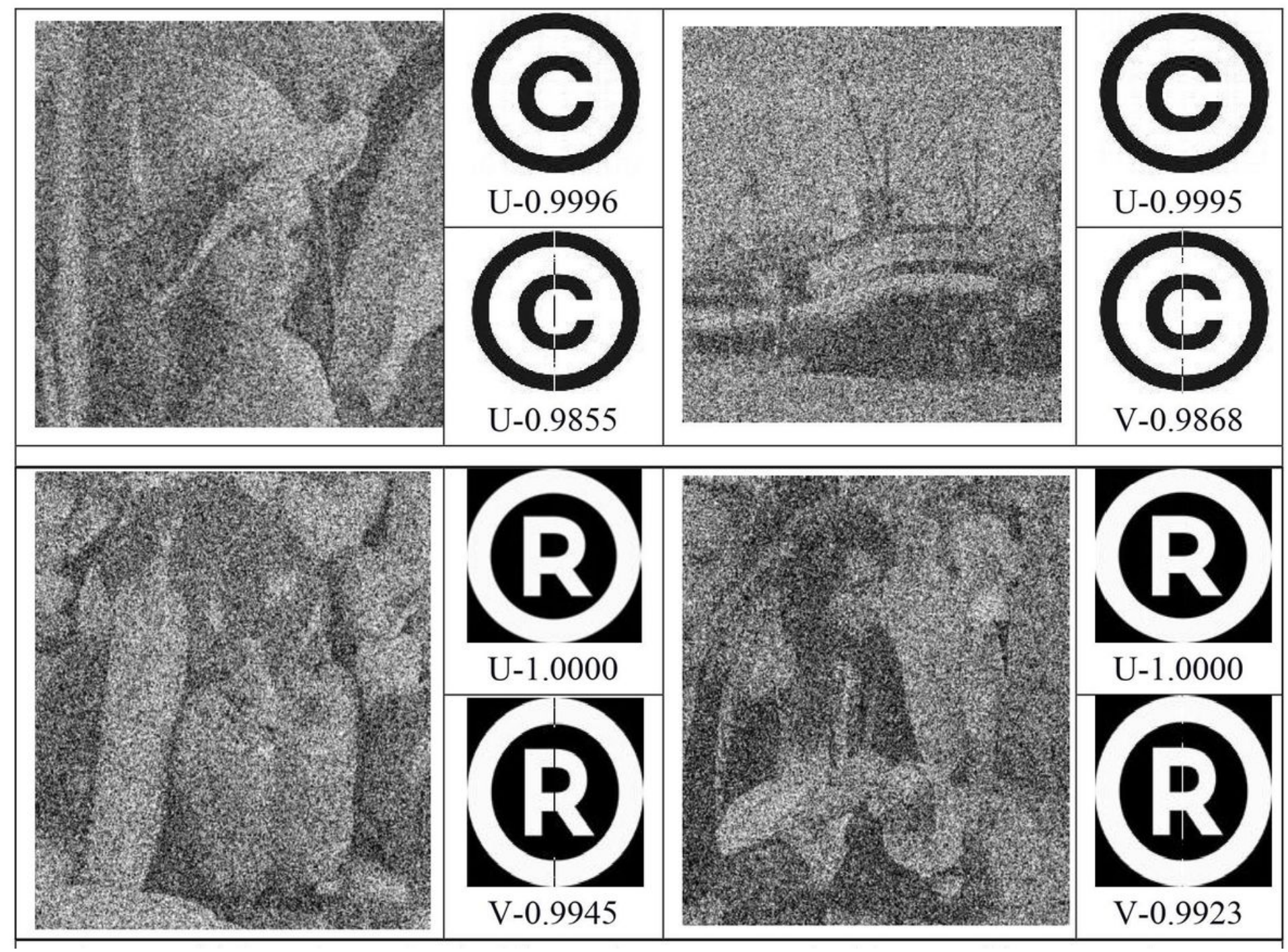

Figure 7

(a)Gaussian Noise (60\%) attack on watermarked images (b) Extracted water marks from $\mathrm{U}$ and $\mathrm{V}$ components 


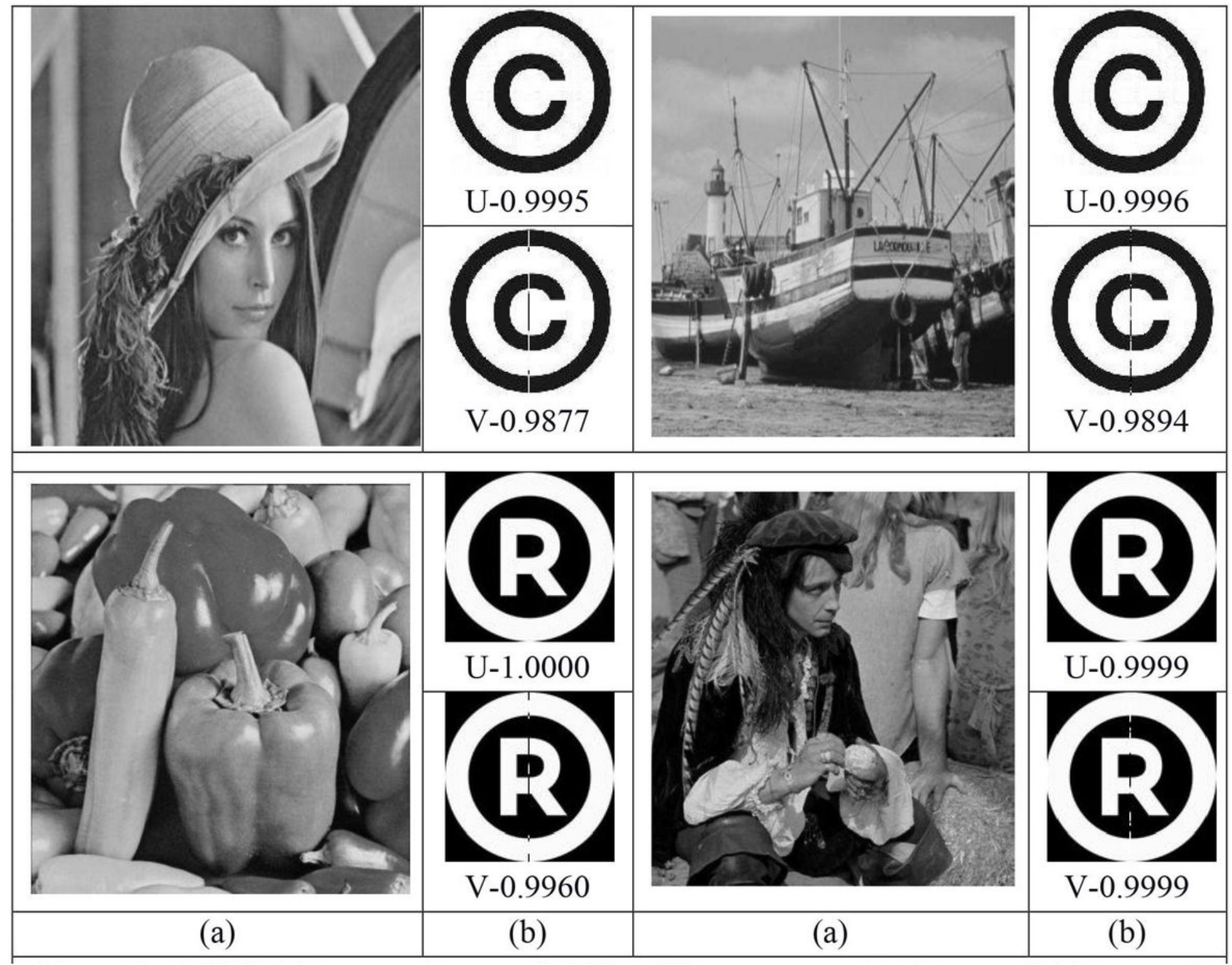

Figure 8

(a)JPEG Compression attack (QF $=50$ ) on watermarked images (b) Extracted water marks from $\mathrm{U}$ and $\mathrm{V}$ components 


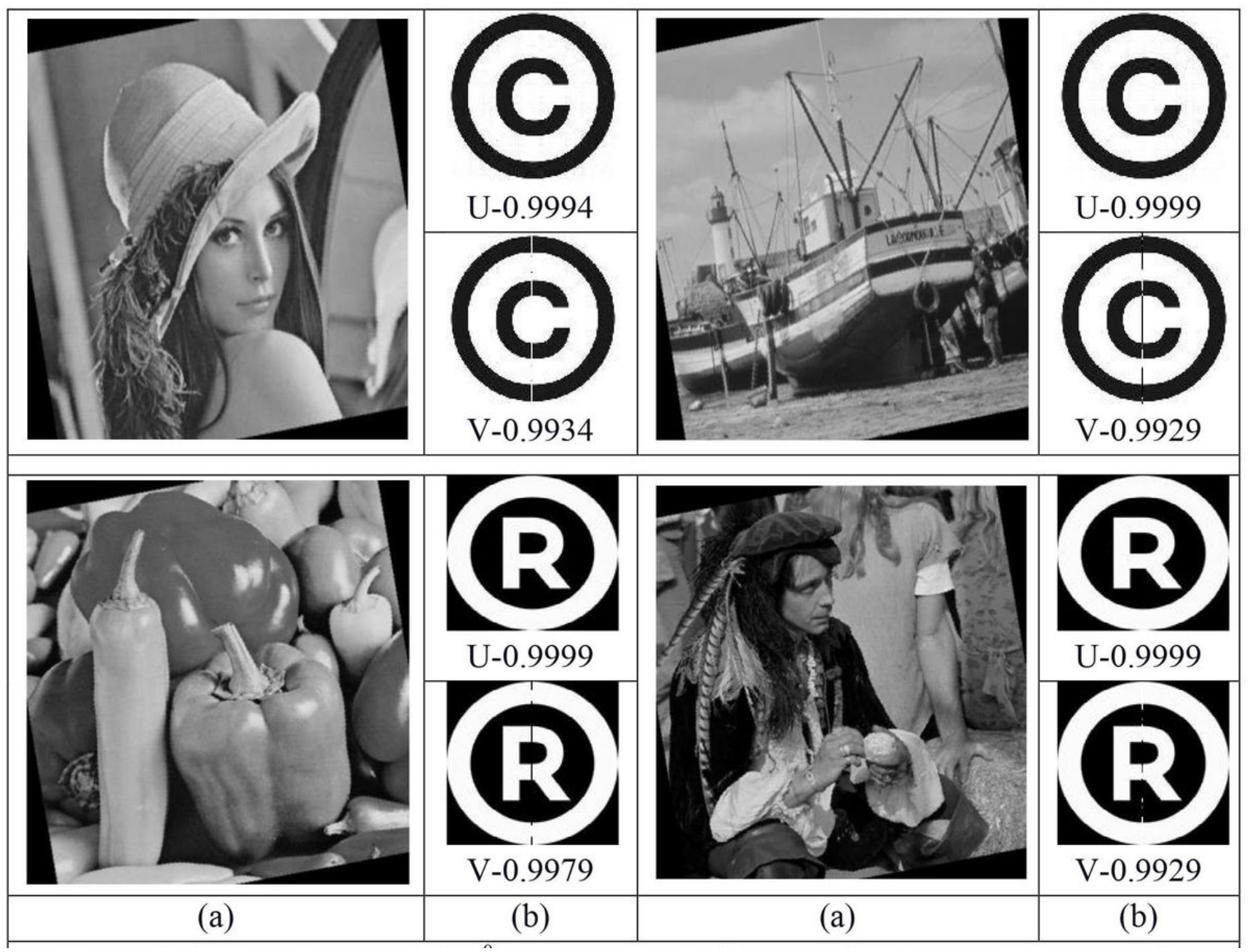

Figure 9

(a)Rotation attack (100) on watermarked images (b) Extracted water marks from $\mathrm{U}$ and $\mathrm{V}$ components 


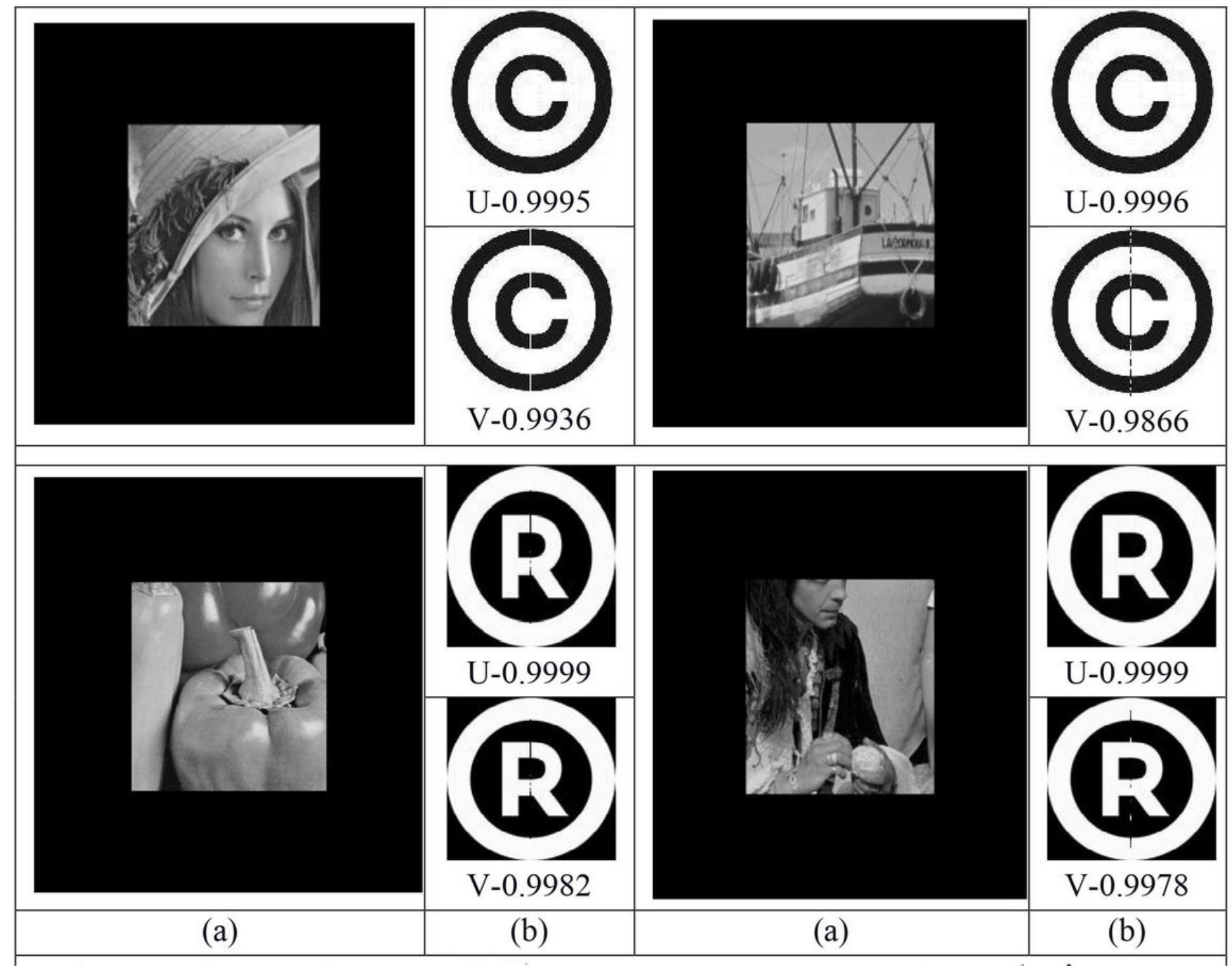

Figure 10

(a) Cropping attack (25\% remaining) on watermarked images (b) Extracted water marks from $\mathrm{U}$ and $\mathrm{V}$ components 


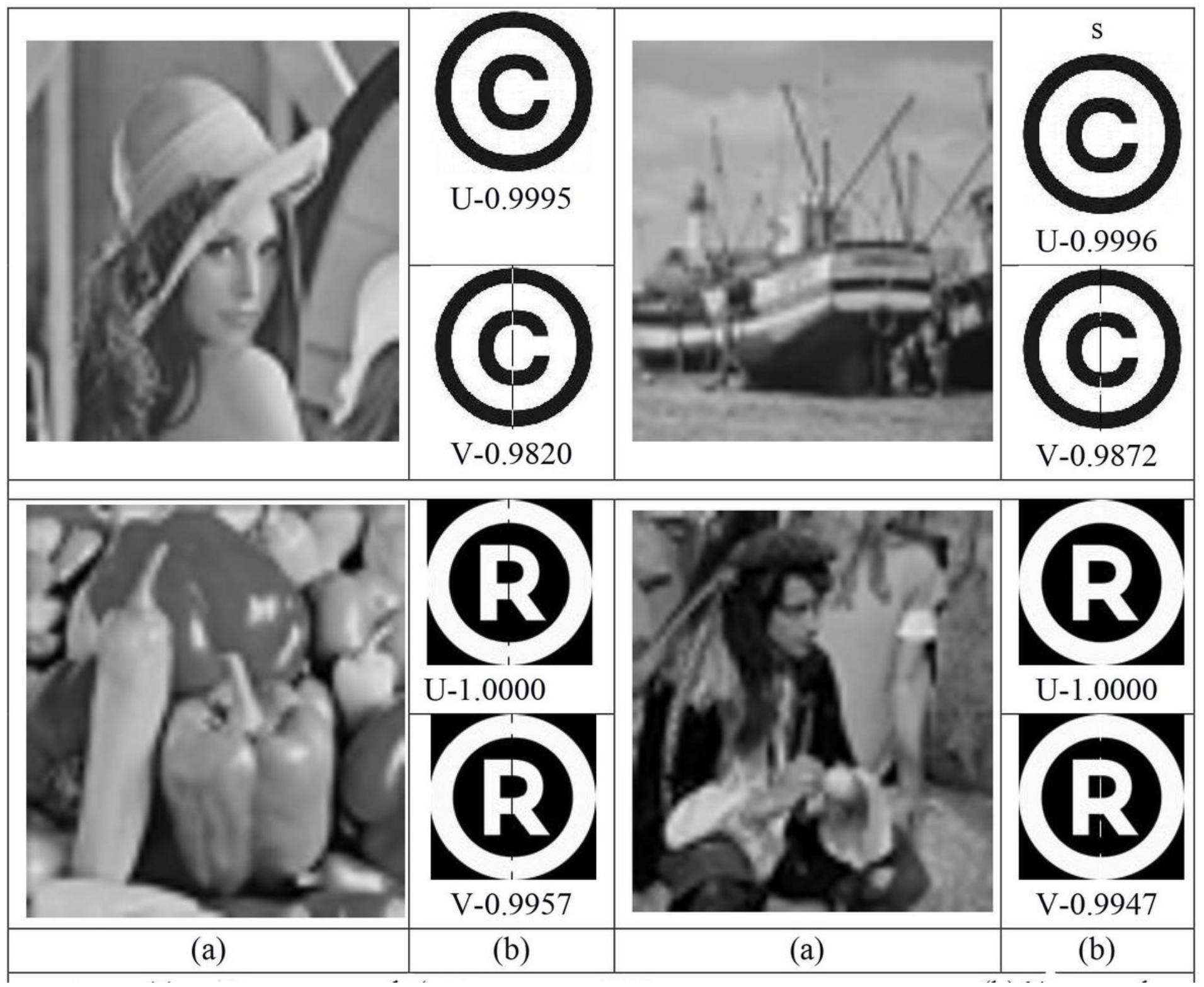

Figure 11

(a)Resize attack (512 -> 64 -> 512) on watermarked images (b) Extracted water marks from U and V components 


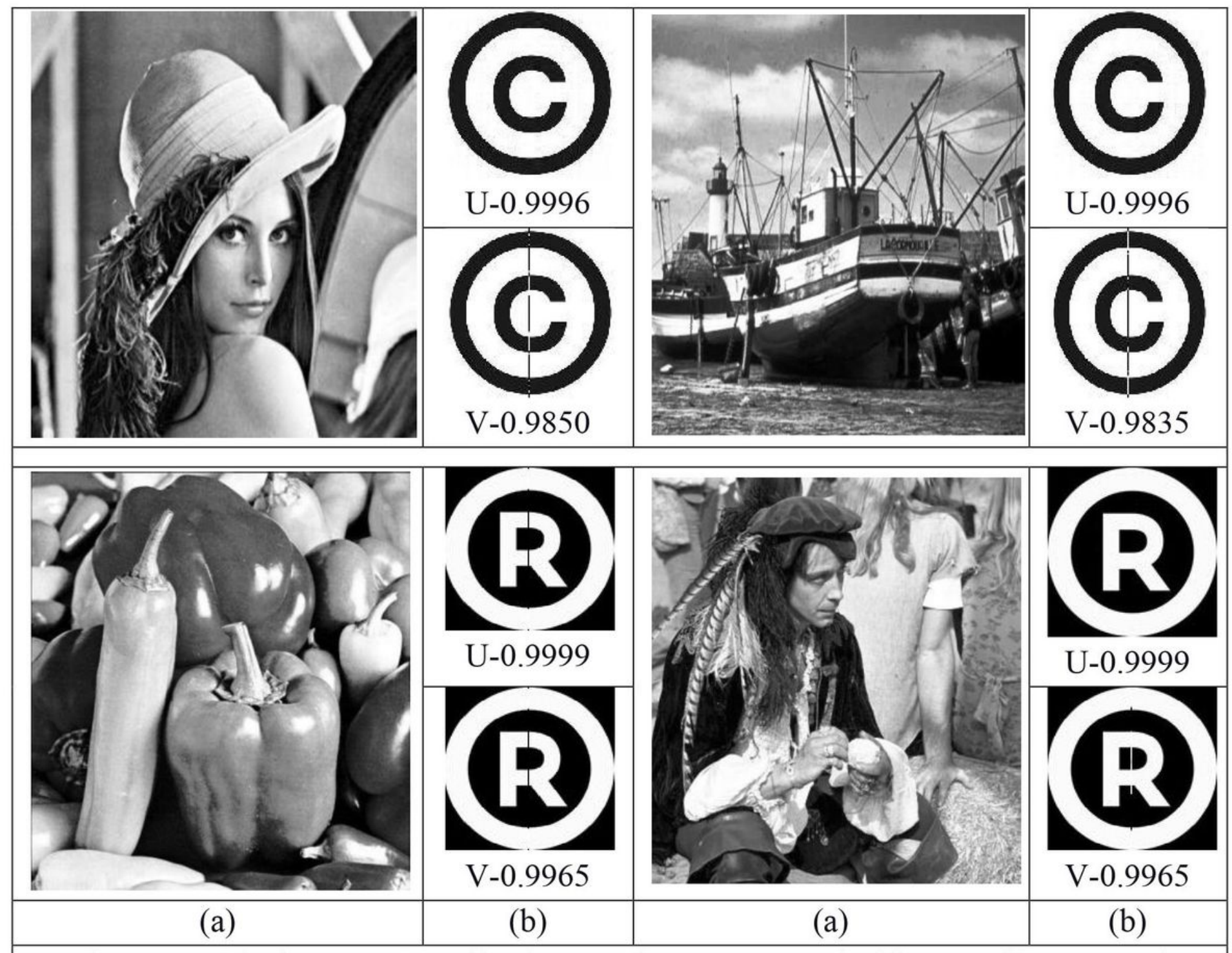

Figure 12

(a)Histogram Equalization attack on watermarked images (b) Extracted watermarks from $\mathrm{U}$ and $\mathrm{V}$ components 


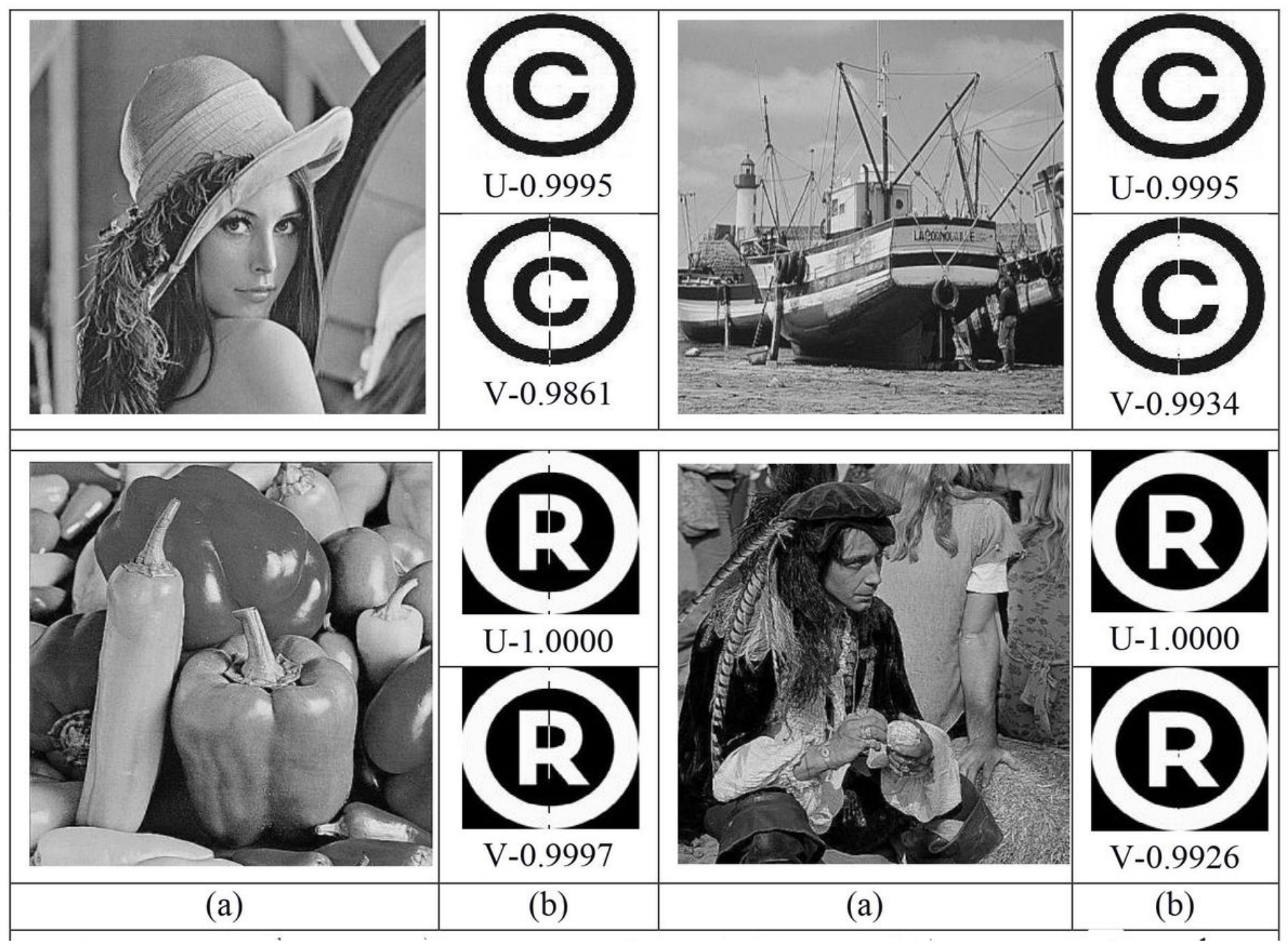

Figure 13

(a)Sharpen (80) attack on watermarked images (b) Extracted watermarks from $\mathrm{U}$ and $\mathrm{V}$ components 